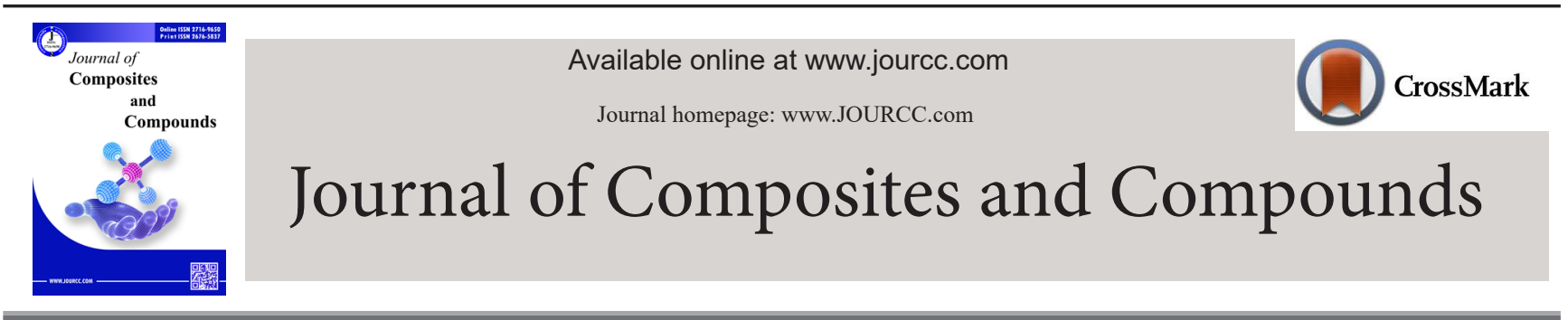

\title{
Application of nano compounds for the prevention, diagnosis, and treatment of SARS-coronavirus: A review
}

\author{
Ahmed Hamad Saleh ${ }^{a}$, Dharmendra Kumar $^{b}$, Ivo Sirakov ${ }^{\circledR}$, Parisa Shafiee ${ }^{d}$, Mehrnoosh Arefian ${ }^{e}$ \\ ${ }^{a}$ Biology Department, College of Science, University of Kirkuk, Iraq \\ ${ }^{b}$ Department of Pharmacy, School of Medical and Allied Sciences, Galgotias University, Gautam Buddha Nagar, Uttar Pradesh, India \\ ${ }^{c}$ Medical University of Sofia, Faculty of Medicine, Department "Medical Microbiology", 2 "Zdrave" St., Post code 1431, Bulgaria \\ ${ }^{d}$ Catalyst and Nano Material Research Laboratory (CNMRL), School of Chemical, Petroleum and Gas Engineering, Iran University of Science and \\ Technology, Tehran, Iran \\ ${ }^{e}$ Department of Biochemistry, Islamic Azad University, Falavarjan Branch, Isfahan, Iran
}

\begin{abstract}
A B S T R A C T
Coronavirus disease, also called COVID-19, a universal health concern, has affected more than 200 countries after Article history:

its declaration as a pandemic on 11 March 2020 by the World Health Organization, WHO. COVID-19 results due Received 3 August 2021

plays an important part in the diagnostics, prevention, and therapeutic approaches for controlling COVID-19.

The development of nanomaterials for viral disease is based on preventive measures and disinfectants, diagnostic

devices, and therapeutic drugs or vaccines to transfer antiviral drugs into the human body. Being at the same

scale as viruses, nanoparticles can replicate the functional and structural properties of viruses, and nanomaterials

can be the best substitute for developing vaccines. A broad range of nanostructures, including gold, silver, zinc,

graphene, carbon, liposomes, and polymeric compounds, have antiviral activity and can be employed in vaccine

development or inactivation of the virus.

(C)2021 JCC Research Group.

Peer review under responsibility of JCC Research Group
\end{abstract}

A R T I C LE IN F O RM A T ION

to SARS-CoV-2 entrance into the epithelial cells of the human's lung. Recently, nanotechnology has turned to be Received in revised form 27 September 2021

a great promising method used in the medical field regarding viruses. By mitigating infection, nanotechnology Accepted 19 December 2021

Table of contents

1. Introduction

2. SARS-CoV-2 and Outbreak of SARS-CoV-2

Keywords:

SARS-coronavirus

Nanocompounds

COVID-19

Nanotechnology

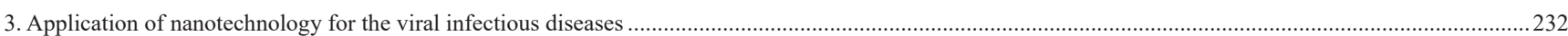

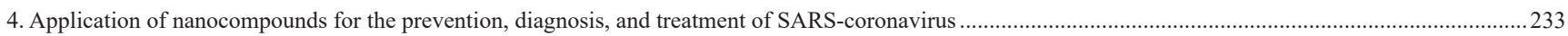

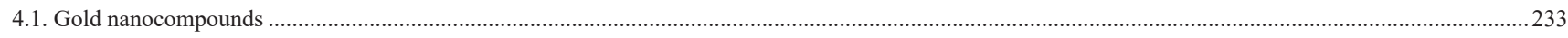

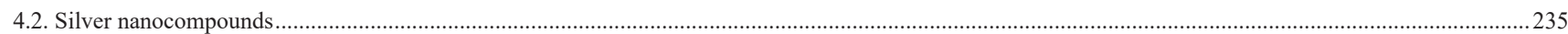

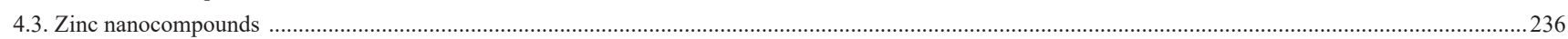

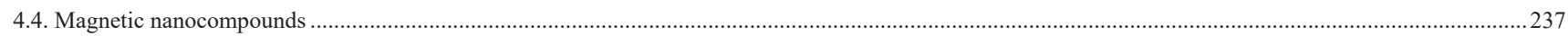

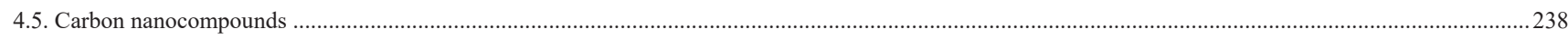

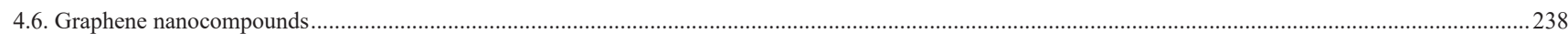

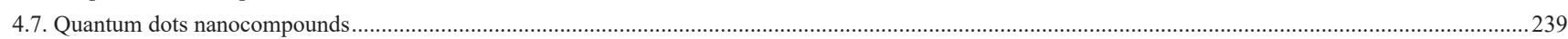

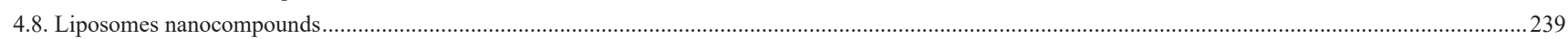

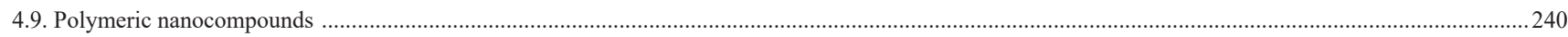

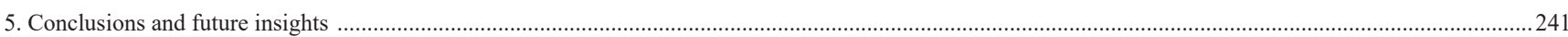

\section{Introduction}

The COVID-19 is a result of the severe acute respiratory syndrome coronavirus 2 or SARS-CoV-2 and has come to be a major concern of global health [1]. The nano-sized SARS-CoV-2 (100-160 nm) has a positive-stranded 27-32 kb RNA genome [2]. The COVID-19 outbreak has been announced as a pandemic by the World Health Organization (WHO) on 11 March 2020 [1]. The COVID-19 occurs by the entrance of the virus to the epithelial cells of the human lung via the S protein, interacting with the human receptor angiotensin-converting enzyme 2 receptor protein (ACE2) [3].

The outbreak of the COVID-19 was first reported in Wuhan city in

\footnotetext{
* Corresponding author: Parisa Shafiee; E-mail: Parisashafiee603@gmail.com

https://doi.org/10.52547/jcc.3.4.4 This is an open access article under the CC BY license (https://creativecommons.org/licenses/by/4.0)
} 


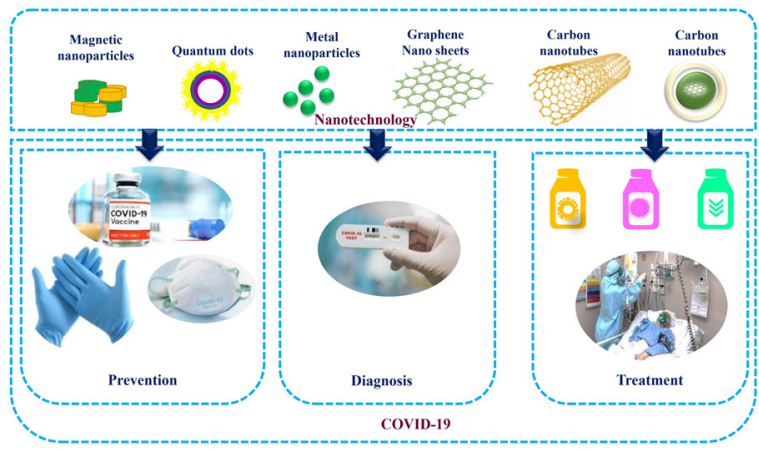

Fig. 1. Use of nanotechnology in COVID-19 diagnosis, prevention, and treatment.

December 2019 while SARS-CoV-2 was speedily transferring across the world and even in a few animals such as bats, camels, and cats. Currently, SARS-CoV-2 could transfer from animals to humans and among humans resulting in respiratory issues [4]. Moreover, this virus could be active for several hours on surfaces like cloths, plastics, papers, and metals based on humidity, temperature, topological and chemical behavior of the surface. Touching these surfaces, followed by touching the mouth, nose, or eyes, can also transmit the virus [5]. The genome of COVID-19 has contained $\sim 30000$ nucleotides. It has been encoded via four structural proteins, including Envelop (E) protein, Spike (S) protein, Membrane (M) protein, and Nucleocapsid (N) protein. The capsid includes the protein shell, and there is N-protein or nuclear capsid into the capsid. It is bound to the single positive-strand RNA of the virus which makes it possible for the virus to grab the cells of humans and change them into factories of the virus. The viral RNA genome is coated by the $\mathrm{N}$ protein. It has a significant role in its transcription and replication. The N-terminal of the $\mathrm{N}$ protein is binding to subgenomic and genomic RNAs in IBV and MHV virions, and then processes the viral transcription and replication [6]. The majority of patients infected by COVID-19 experience mild symptoms including shortened breath, fever, and cough, as stated by the Centers for Disease Control and Prevention; nevertheless, $20 \%$ of patients express acute signs including pneumonia and respiratory issues or even death [7]. Currently, nanotechnology presents a crucial role to solve health problems regarding viruses. However, the fast advancement of drug resistance to recently available treatments and unfavorable influences owing to extended use is a significant public health problem. The advancement of new therapy techniques is needed. The nanostructure interactions with microorganisms cause the rapid revolution in the biomedical area via providing benefits in both therapeutic and diagnostic fields. Nanoparticles present desirable physical characteristics which have relataed to advantages for drug delivery. These are mainly because of the extended drug payloads, adjustable surface charge of the particle with the feasibility of encapsulation, large surface area to volume ratio (enhanced solubility compared to larger particles), and particle size (that influences circulation time and bioavailability) which can be fitted. These features make nanoparticulate drug delivery systems as the favorable candidates to improve and/or achieve therapeutic impacts which are despite of similar bulk composites [8]. For example, nanotechnology has provided a potent approach for alleviating infections by preventing, diagnosing, and treating COVID-19. These methods consist of the advent of nanomaterial-based strategies for providing: (i) preventive disinfectants and measures, (ii) fast and accurate diagnostic devices, and (iii) vaccines or therapeutic agents to supply antiviral factors. Nanoparticles (NPs) and viruses possess the same size range, which provides them with the ability to reproduce the functional and structural characteristics of viruses and makes nanotechnology very influential in vaccine evolution and immuno-engineering [9]. Nanomaterials largely contribute to the advent of new drugs against viruses. A wide variety of metal NPs

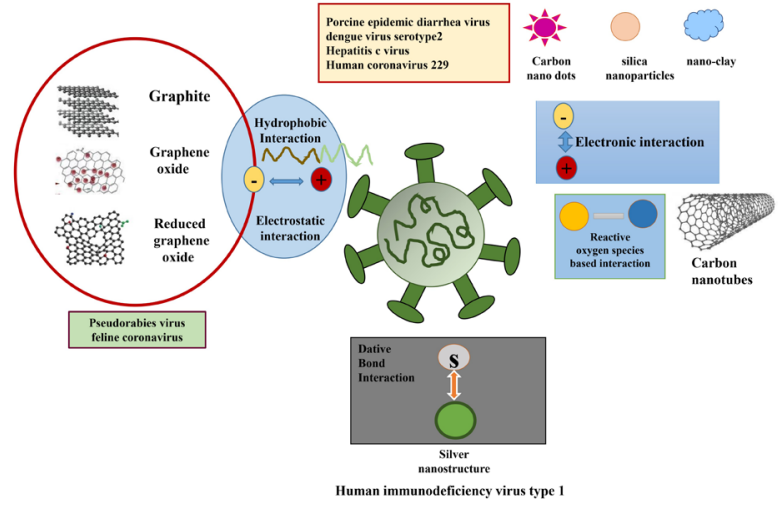

Fig. 2. A variety of NPs used against viruses.

present an antiviral effect and can interact with nanocomposites through the host cell receptors, leading to the virus inactivation or blockage of the virus entrance in the host cell $[4,10]$. The special properties of nanomaterials, including size, enhanced solubility, and multi-functionality, presents efficient gene modification, drug delivery, and ideal interactions between capturing molecules of sensors and targeted analytic [11].

This review focuses on the role of nanotechnology in the prevention, diagnosing, and treating of COVID-19. The latest advances in nanotechnology for COVID-19, as well as a comprehensive survey on their application and performance, have been provided. The review begins with an outline of the COVID-19 outbreak and SARS-CoV-2. Then, the applications of various nanocompounds, including metal, magnetic, carbon, graphene, quantum dots, liposomes, and polymeric-based nanocompounds in fighting COVID-19, are comprehensively discussed regarding the three primary challenges of prevention, diagnosis, and treatment. The benefits of each nanomaterial are discussed for preventing the spread of COVID-19 (using protective tools and vaccines), diagnosing (using nucleic acid and antibody detection), and treating methods (using nanodrugs). Finally, the main challenges and future of nanotechnology for managing COVID-19 are studied.

\section{SARS-CoV-2 and Outbreak of SARS-CoV-2}

Some local health authorities stated various patient groups diagnosed with unknown pneumonia which were related to a seafood shopping center in Wuhan, China in the last days of December 2019 [12]. Local hospitals identified COVID-19 using a monitoring approach for "pneumonia of unidentified etiology," previously established in 2003 after the outbreak of COVID-19 [13]. The WHO declared that COVID-19 is a "public-health emergency of international concern" on 30 January 2020 [14]. Several cases with unknown pneumonia have been repeatedly reported in a few hospitals in Wuhan city. A large number of patients were exposed to a seafood marketplace in Wuhan city. Afterward, the virus has been spread across the world, and the pandemic is growing rapidly, and groups of patients with no traveling history to Wuhan have been appeared [15].

The simultaneous emergence of this virus outbreak with the lunar New Year increased the number of travels between cities, resulting in the spread of the virus to other cities of China. A month after, this virus spread significantly to all provinces of China. The International Committee on Taxonomy of Viruses called the newly-emerged coronavirus 'SARS- CoV-2' on 11 February, and the WHO designated it as 'COVID-19'. Since 11 March 2020, despite the efficient control of COVID-19 in China, the number of cases has risen rapidly in the USA, Europe, and other countries. Based on the online instant reports of the 


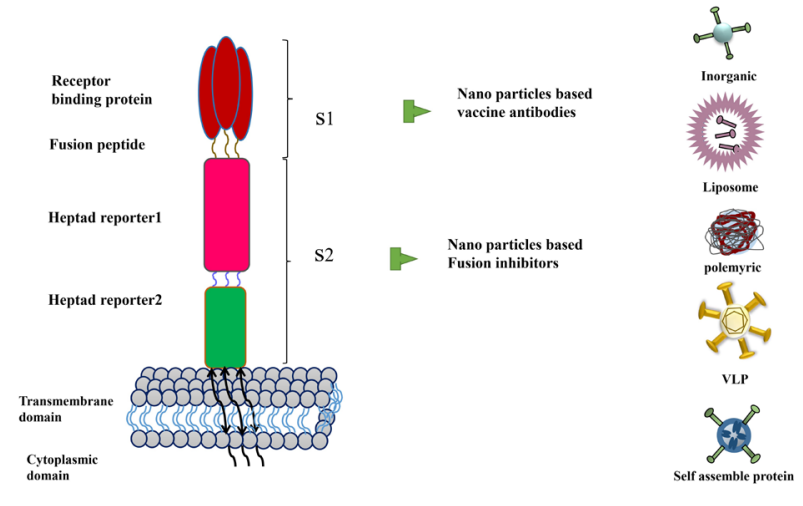

Fig. 3. Schematic of targets in SARS-CoV-2 treatment using NPs.

Center for System Science and Engineering at Johns Hopkins University, more than 200 countries in six continents have announced over 200 million patients of COVID-19 until 22 August 2021, and more than 4 million patients had died. The country with the highest number of cases is the USA up to now [2]. The European Centre for Disease Prevention and Control (ECDC) has now evaluated the risk level from moderate to high [15].

SARS-CoV-2 is an enveloped, non-segmented, single-stranded positive-sense RNA virus with coronas on its surface [16]. This type of virus has four basic structural proteins: envelope (E) glycoprotein, nucleocapsid (N) protein, spike (S) glycoprotein, and membrane (M) glycoprotein [17]. Also, the major target proteins of SARS-CoV-2 are mainly viral spike proteins [18], 3-chymotrypsin-like protease (3CLpro), 3 CL hydrolase [18], papain-like protease (PLpro), RNA-dependent RNA polymerase [19], envelop proteins [20], 2'-O-ribose methyltransferase [21, 22], nonstructural protein-3 (Nsp3) [23], and nucleocapsid protein [24]. The SARS-CoV-2 genomes are the same as other coronaviruses. The ACE2 receptors existing on the host cells are the major target of this virus. The SARS-CoV-2 connects to the ACE2 receptor of the host cell via its $\mathrm{C}$-terminal domain (CTD) and receptor binding domain (RBD) composed of envelop-embedded S-protein [25-27]. The initial step of infection includes the attachment of S-protein to ACE2 receptor. Thus, treating the related disease comprises of targeting this binding process [28]. The virus entrance into a cell is promoted through transmembrane serine protease 2 (TMPRSS2) via protease function. After this, the virus enters endosomes. Because of the low $\mathrm{pH}$ of endosomes, the uncovered viruses secrete the genome for synthesizing proteins, which provides protein and viral RNA, generating additional infectious species and emitting them into the host cell [29-32].

\section{Application of nanotechnology for the viral infectious diseases}

Due to the nano size of coronaviruses, nanotechnology has a great potential to grasp the lifespan, structure, and growth of this virus. Nanotechnology can provide novel and affordable detection approaches for the development of protective tools and equipment as well as new efficient medical help. The role and capacity of nanotechnology will be discussed in the following sections to deal with the main features of COVID-19 [33].

The occurrence of COVID-19 cases has risen at a shocking rate. Prevention methods of pandemics involve applying pharmaceutical (antiviral drugs and vaccines) as well as non-pharmaceutical remedies. As sufficient pharmaceutical remedies are not normally available immediately, non-pharmaceutical measures are suggested as a vital procedure.

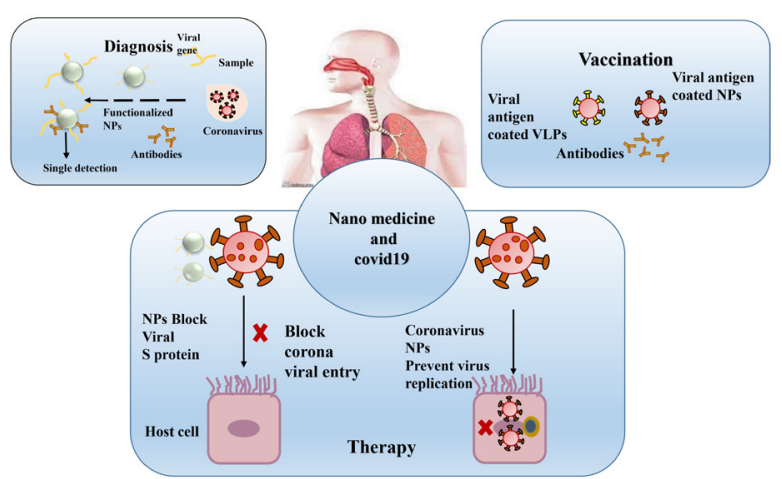

Fig. 4. The mechanism of nanomedicine for diagnosing, preventing, and treating COVID-19.

In this respect, nanotechnology provides novel possibilities to advent approaches for COVID-19 prevention. Some examples of these procedures are masks, disinfectants, and nano carriers for vaccines [34].

Nanomedicine, armed with a multivalent antigen presentation as well as antigens stabilization, could contribute to the administration, design, and delivery of COVID-19 vaccines. Moreover, they transport adjuvants to stimulate immune activity and antigens delivery, including an mRNA vaccine transmitted by liposomal NPs. The subunit and traditional vaccines show limitations like limited immunogenicity or reversion to pathogenic virulence. However, these issues could be addressed by using NPs and altering their characteristics, including shape, size, and surface immunogenicity. Nevertheless, some researchers have reported NPs toxicity [35-38].

The rapid spread of new diverse viruses needs modern remedies. The primary restriction of contemporary antiviral therapies is low specificity, causing the cytotoxicity of host cells. Nanotechnology generates a new possibility for antiviral treatment. The flexibility of NPs makes them adjustable for curative drug delivery and targeting the virus. Application of NPs for fighting against SARS-CoV-2 may consist of methods that prevent the entrance of virus in the host cell thereby causing viral deactivation. The prevention of the proteins of viruses can cause the death of the virus; thus, targeting NPs, special to virus expressed proteins, can reduce the viral incorporation [34].

Viruses are intracellular parasites that could lead to a variety of diseases, such as SARS, Ebola, acquired immune deficiency syndrome (AIDS), flu, chicken pox, and influenza. Viruses possess a limited number of genes for the formation of new viruses, and a large number of them employ enzymes generated by the host cell [39]. Therefore, rapid diagnosis of these diseases is crucial because of the restricted treatment methods. Detection of viruses normally requires particular strategies and facilities such as gene sequencing, nucleic acid detection, hem agglutination assay, antibody detection, and cell culture, which are usually expensive, time-consuming, and labor-intensive [40]. Traditional approaches of COVID-19 detection were based on nucleic acid detection, including RT-PCR with disadvantages like lack of special feature because of resemblance with other viral diseases, great false-negative, time-consuming and limited sensitivity. NPs could limit these issues. Nanotechnology has the potential to detect COVID-19 rapidly, enhancing the efficacy of diagnostic measurements. In this regard, nano-bio sensors are largely precise and sensitive and can identify low amounts of targeted elements or species in bio-samples. A biosensor is a systematic tool composed of biological components such as microorganisms, organelles, cell receptors, enzymes, antibodies, and nucleic acids, which generate thermal, optical, or electrical signals based on the interaction between a transducer and examined component. The obtained signals are then transformed into electrical signs. Biosensors have several clinical and medical appli- 


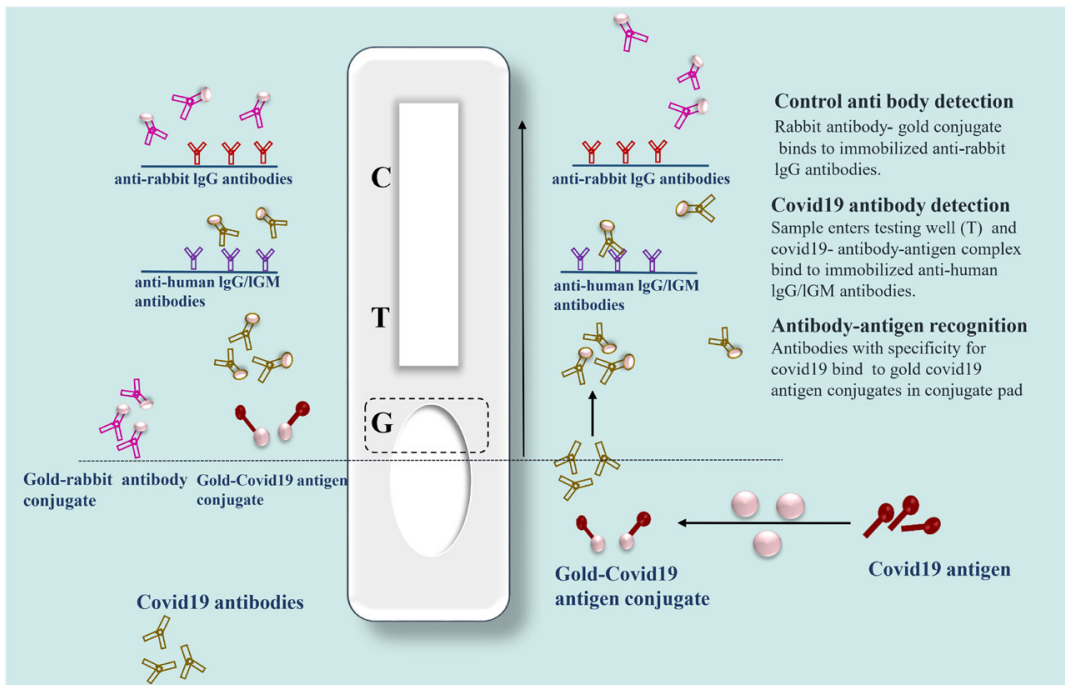

Fig. 5. Diagnosing tests for SARS coronavirus-2. T: Testing well; S: Sample well; G: Conjugate pad; C: Control well

cations such as i) rapid diagnosis and illness therapy, ii) pathogens detection, iii) evaluation of drugs and metabolites, iv) drugs development, v) assessment of drug activity and vi) measurement of analytes [41]. Nanomedicine is efficient in identifying resistant organisms, enabling it to be employed as a prophylactic route for the fast diagnosis of infectious diseases, particularly in newly-emerged infections [37]. The excellent characteristics of nanomaterials have been successfully used in the advent of a broad variety of molecular and serological detection approaches for virus isolation. These nanomaterial-based methods were widely used in identifying and understanding MERS (Middle East respiratory syndrome) and SARS viruses, relatives of SARS-CoV-2, accountable for local outbreaks in recent years and are also being utilized to grasp the life cycle and structure of SARS-CoV-2 [33]. Fig. 1 indicated the most developments of nanotechnology in COVID-19 based on main three classifications: diagnosis, prevention, and treatment.

\section{Application of nanocompounds for the prevention, diagnosis, and treatment of SARS-coronavirus}

Nanotechnology can be used in various fields such as agriculture, health, defense, etc. Nanotechnology provides low-cost, reliable, and influential methods for the diagnosis and treatment of various severe diseases. In the last years, the excellent research has been done on nanotechnology for enhancing the efficiency of the therapeutics for different indications, which can be advanced to COVID-19 [42]. For instance, Novavax, Inc. has fabricated a nanoparticulate vaccine via antigens extracted from the coronavirus $\mathrm{S}$ protein that is stably expressed in the system of baculovirus [43]. Metal and non-metal NPs like nano clay [44],

Table 1.

Nanomaterials are used for inhibiting various viruses.

\begin{tabular}{|c|c|c|c|}
\hline S. No & Nanomaterial & Virus & Interaction \\
\hline 1 & $\begin{array}{c}\text { Multiwall carbon } \\
\text { nanotubes }\end{array}$ & Influenza strain X-31 & $\begin{array}{c}\text { Reactive oxygen } \\
\text { species }\end{array}$ \\
\hline 2 & Silver NPs & $\begin{array}{l}\text { Human immunodefi- } \\
\text { ciency virus type } 1\end{array}$ & $\begin{array}{c}\text { Deactivate } \\
\text { bonds }\end{array}$ \\
\hline 3 & $\begin{array}{c}\text { Nano clay and its } \\
\text { composites, silica } \\
\text { nanoparticle, carbon } \\
\text { nanotubes }\end{array}$ & $\begin{array}{c}\text { Human coronavirus } \\
229 \mathrm{E} \\
\text { Hepatitis C virus } \\
\text { Dengue virus serotype } 2 \\
\text { Protein epidemic diar- } \\
\text { rhea virus }\end{array}$ & Electrostatic \\
\hline 4 & $\begin{array}{l}\text { Reduced graphene } \\
\text { oxide, graphene oxide, } \\
\text { graphite }\end{array}$ & $\begin{array}{l}\text { Pseudorabies virus } \\
\text { feline coronavirus }\end{array}$ & $\begin{array}{l}\text { Hydrophobic } \\
\text { and Electrostatic }\end{array}$ \\
\hline
\end{tabular}

zinc oxide nanoparticles [45, 46], copper oxide nanoparticles [47], silver nanoparticles [48], magnetic nanoparticles [49], gold nanoparticles [50], silica nanoparticles [51], graphene oxide [52] and carbon nanomaterials [53] act successfully in deactivating the COVID-19 (Fig. 1) [54]. Inorganic NPs (INPs) with properties including controllable composition, shape and size, great surface-to-volume ratio, luminescence, and the capacity to reveal multiple reciprocal sites on the surface, are promising in this area [55].

The initial stage of viral infection is the binding of the virus to the host cells. NPs could prevent the adherence of viruses to the host cell [55]. The NPs interact with virus elements via electrostatic interaction, dative bond, and interaction, hydrophobic interaction or reactive oxygen interaction $[41,56]$. Table 1 illustrates a variety of nanomaterials utilized for preventing different viruses. Detection and inhibition of viruses could also be performed by employing nanomaterials as outward incentives in biosensors. Different elements of the virus join with nanomaterials and act as an exterior spur, resulting in signal detection [57].

Nanomaterials like nanofibers are generally utilized in masks to limit enormous respiratory droplets dispersion and shield individuals against droplet spread. Filters composed of polypropylene microfibers and electrostatic charges are applied for filtering masks (e.g. N95, FFP2, and FFP3) with great performance. The function of masks against viruses and microbes has been improved through the use of nanofibers, nanofiber webs, and antimicrobial materials [58]. Besides masks, nanomaterials have been employed in the preparation of medical gloves for shielding against COVID-19 [59]. Organic NPs have been used for transporting antiviral drugs like dapivirine, efavirenz, zidovudine, and acyclovir to improve drug delivery, drug bioavailability, and targeted antiviral function [60]. Antimicrobial drugs including ribavirin, ritonavir, remdesivir, chloroquine, and lopinavir have been examined in clinical tests of COVID-19 and have presented beneficial outcomes against SARS-CoV-2 [34]. The targeted ligand conjugated nanoparticle specially binds with virus epitopes which lead to virus inactivation, prevent the virus from entering the cells. Hence, the infection can be neutralized with nanomedicine-based procedures [54]. A variety of NPs used against viruses was depicted in Fig. 2.

\subsection{Gold nanocompounds}

Gold NPs (AuNPs) are widely utilized in nano vaccines due to their beneficial properties, such as providing immunization and carrying antigens [61]. Virus-like particles VLPs can be formed by incubating AuNPs as a core with $\mathrm{CoV} \mathrm{S}$ proteins (such as $\mathrm{S}$ protein of avian $\mathrm{CoV}$ ), which spontaneously functionalize the surface (S-AuNPs). Vaccines based on S-AuNP could improve the delivery of lymphatic antigen and elevate 


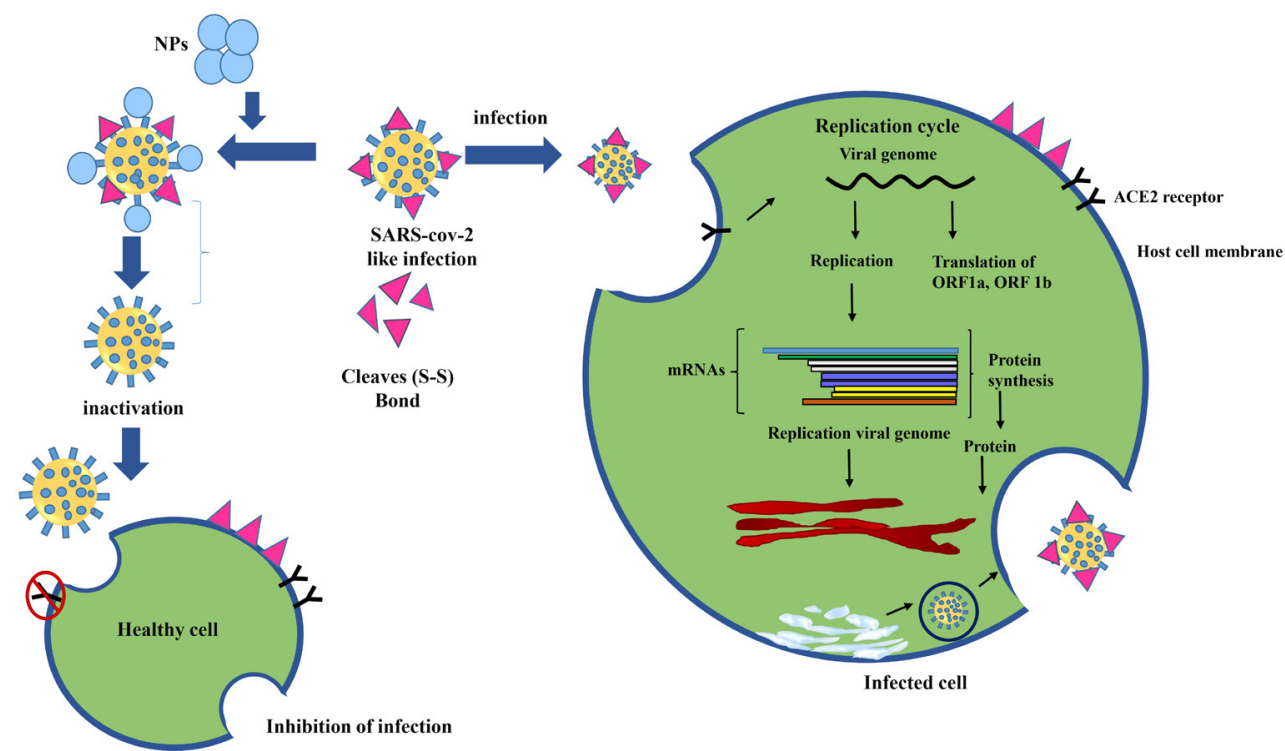

Fig. 6. The role of nanomedicine and replication cycle in neutralizing virus-based diseases like SARS-CoV-2.

humoral and cellular response relative to free antigens [62]. This vaccine can be employed for other pathogenic CoV. Likewise, a vaccine based on S-AuNPs has been prepared for SARS-CoV prevention [63]. The prepared vaccine was capable of triggering a powerful $\operatorname{IgG}$ response. AuNPs can also be tailored to detect CoV-based antibodies via electrochemical immunosensor test, which is composed of carbon electrodes including a set of AuNPs [64].

AuNPs could be simply modified for intranasal transmission and present the benefit of easy diffusion into lymph nodes and stimulating CD8+(T-killer) cell-mediated immune response [65]. Moreover, AuNPs, with regrad to their large atomic number, could operate as extremely biocompatible and persistent contrast agents of X-ray for medical imaging in Computed Tomography (CT) [66]. AuNPs are also assessed as siRNA-carriers and target-specific gene silencing due to their flexibility, biocompatibility, and efficient delivery approach [67]. Huang X. et al. demonstrated that the heptad repeat 1 (HR1) peptide inhibitor provided 10 times improved inhibitory function when transferred by gold nanorods in comparison with free $\alpha$-helix peptide (PIH) [68]. Additionally, these nanocompounds presented elevated stability and biocompatibility for treating patients diagnosed with MERS-CoV and other coronaviruses. In another study, Chen H. et al. mixed 100-nm- AuNPs with the $\mathrm{S}$ protein of infectious bronchitis virus and expressed that AuNPs enhance the delivery ability, particularly in the lymphatic system, leading to enhanced absorption by cells and increased complement function-[69].

AuNPs have also been used in bio sensing and presented efficiency in increasing biosensors' detection limit [70, 71]. The electronic, optical characteristics of AuNPs could be detected via various biosensors such

Table 2.

Nanomedicine as a promising approach for diagnosis, treatment, and prophylaxis against COVID-19.

\begin{tabular}{|c|c|c|c|c|c|}
\hline & Platform & $\begin{array}{l}\text { Antigenic } \\
\text { component }\end{array}$ & Virus & Notes & Ref. \\
\hline \multirow{2}{*}{$\stackrel{\infty}{\hat{Z}}$} & $\mathrm{~S}-\mathrm{Au}$ NPs & $\begin{array}{l}\text { Spike protein of } \\
\text { avian } \mathrm{CoV}\end{array}$ & Avian $\mathrm{CoV}$ & $\begin{array}{c}\text { Significant } \\
\text { improvement } \\
\text { in vaccination } \\
\text { potency }\end{array}$ & [133] \\
\hline & S-Au NPs & Spike protein & SARS-CoV & $\begin{array}{l}\text { Induced strong } \\
\text { IgG responses } \\
\text { Lung eosino- } \\
\text { philic immuno- } \\
\text { pathology }\end{array}$ & [6] \\
\hline
\end{tabular}

as colorimetric and electrochemical ones [72]. AuNPs have specific optical properties, including localized surface plasmons (LSPs), leading to wavelength-selective intake with highly immense molar extinction coefficients and excellent improvement of the regional electromagnetic field near the AuNPs surface [73, 74]. Electrochemical sensors are efficient in discovering viruses because of their elevated sensitivity and shrinkage. The application of AuNPs in these sensors is far more efficient in detecting viruses by immobilizing biomolecules whilst sustaining their performance [75].

The application of gold nano rods in antiviral-based treatments for MERS-CoV has been successful. After the entry of the virus into the host cell, the infection could be inhibited using NPs, acting as antiviral carriers [76]. AuNPs with relevant antigenic moieties has been assessed as promising vaccines for fighting against viruses [77].

Additionally, INPs have small sizes as well as extremely active surfaces, clarifying their use in diagnosis devices [78]. For example, an extremely sensitive AuNPs-based electrochemical immunosensor was utilized to identify MERS-CoV at low amounts $(0.4 \mathrm{pg} / \mathrm{ml})$, which was achieved because of the outstanding electronic and optical characteristics of AuNPs, increasing as a result of the great surface area/volume ratios [75]. Jung et al. [79] introduced Gold Nanorods (GNRs)-based therapy accompanied with plasmonic photo thermal therapy. GNRs presented convenient properties in-vivo, and PEGylated GNR concentration (48 $\mathrm{Qu} / \mathrm{ml}$ ) caused appropriate temperature for the in vivo assessments. The obtained moderate hyperthermia enhances the cellular uptake rate of NP-loaded vaccines and drugs via the improved internalization through clathrin-mediated endocytosis. The mentioned photo thermal treatment could be evaluated for prohibiting in-cell viral replication opposing SARS-CoV-2. AuNPs functionalized with the influenza peptide consensus M2e rest at the C-terminal through thiolate-Au. Nasal uptake of $\mathrm{M} 2 \mathrm{e}-\mathrm{AuNPs}$ in mice is associated with a cytosine-guanine-rich oligonucleotide presented a powerful immune activity as opposed to the influenza virus PR8 strain [80]. In Fig. 3, targets for nanotherapeutics against SARS-CoV-2 were illustrated. Different nanoplatforms, displaying relevant antigenic moieties, including inorganic (gold and silver) NPs, polymeric NPs, Virus-Like Particles (VLPs), liposomes, and self-assembled protein NPs have been studied as potential viral vaccines formulations (Figure 1).

As the current COVID-19 diagnosing approach based on nucleic acid may cause false negatives and is challenging for being employed for every patient due to the asymptomatic carriers, a colloidal AuNPsbased lateral flow test was evolved to obtain a fast diagnosis of the 

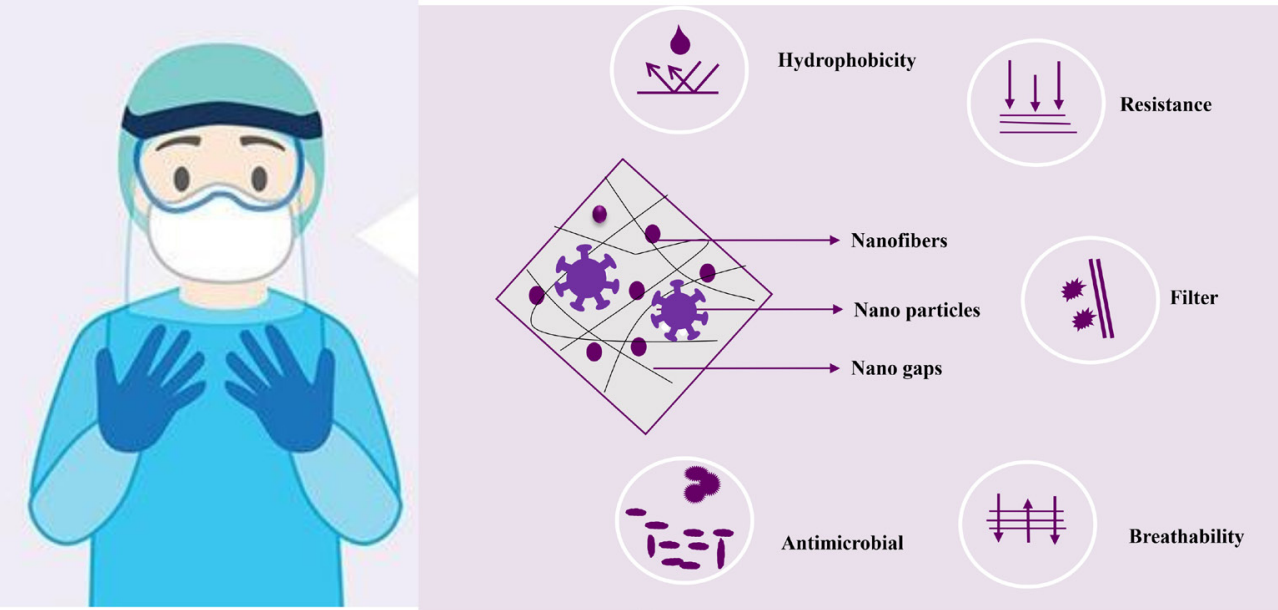

Fig. 7. Nanotechnology applications for preparation of PPE Kit.
IgM antibody fighting the SARS-CoV-2. AuNPs-LF test had a sensitivity of $100 \%$ and presented great selectivity for detecting IgM for the SARS-CoV-2 without any interference with other viruses. AuNPs-LF test provided results in $15 \mathrm{~min}$ and required as low as $10-20 \mu \mathrm{L}$ serum. Overall, this test has several advantages, including high stability and specificity, simple operation, low price, and low detection time, making it a convenient experiment for COVID-19 diagnosis in hospitals, particularly in emergency sections requiring several tests [81]. Fig. 4 shows the mechanism of nanomedicine for diagnosis, vaccination, and therapy. Nanoparticles-based vaccination against coronavirus reported in . Detection strips of NP-based flow as the remarkable procedures to monitor the disease for SARS-CoV-2 have been advanced to rapid monitoring and prevention of necessity to transfer the samples to specific facilities (Fig. 5) [64].

\subsection{Silver nanocompounds}

Silver NPs are known for their excellent antimicrobial activity, which are active ingredients of pharmaceutical materials, including silver-sulfasalazine [76]. These NPs have been employed for treating wounds and burnt tissues. In addition, silver has presented antibacterial, antifungal, anti-angiogenesis, antiplatelet, anti-inflammatory, and anti-cancer properties. Silver NPs are under evaluation for antiviral function. As coro-

Table 3.

Inorganic nanocarrier's role in treating viruses and SARS-CoV-2.

\begin{tabular}{|c|c|c|c|c|c|}
\hline S.No. & Name of nanomaterials & Strategies used & COVID like respiratory viruses & $\begin{array}{c}\text { Animal model } \\
\text { (Host) }\end{array}$ & Dose \\
\hline 1 & $\begin{array}{l}\text { PLGA nanoparticles } \\
\text { (PLGA-KAg) }\end{array}$ & $\begin{array}{l}\text { Induced cross-protective } \\
\text { cell-mediated immune } \\
\text { response }\end{array}$ & $\begin{array}{c}\text { Bovine parainfluenza } 3 \text { virus } \\
\text { (BPI3V) Swine influenza virus } \\
\text { (H1N2) }\end{array}$ & Pig & $2 \mu \mathrm{g} / \mathrm{ml}$ \\
\hline 2 & $\begin{array}{c}\text { Ag colloid } \\
\text { \& titanium dioxide } \\
\text { NPs }\end{array}$ & $\begin{array}{l}\text { Prevented the virus } \\
\text { growth }\end{array}$ & $\begin{array}{c}\text { Porcine } \\
\text { epidemic diarrhea virus } \\
(\text { PEDV) \& transmissible gastroenteritis } \\
\text { virus (TGEV) }\end{array}$ & Pig & $\begin{array}{l}\text { 1000-fold } \\
\text { diluted } \\
\text { from } \\
\text { original }\end{array}$ \\
\hline 3 & Ag NPs & $\begin{array}{l}\text { Prevention of cell } \\
\text { apoptosis }\end{array}$ & TGEV & Pig & $\begin{array}{c}3.125-12.5 \\
\mu \mathrm{g} / \mathrm{ml}\end{array}$ \\
\hline 4 & Diphyllin NPs & $\begin{array}{l}\text { Prevention of endosomal } \\
\text { acidification }\end{array}$ & $\begin{array}{c}\text { Feline Infectious Peritonitis } \\
\text { Virus (FIPV) }\end{array}$ & Cat & $2 \mu \mathrm{M}$ \\
\hline 5 & $\mathrm{GO} / \mathrm{Ag}$ nanocomposite & Antiviral activity & Feline coronavirus & Cat & $0.1 \mathrm{mg} / \mathrm{ml}$ \\
\hline 7 & Ag2S nanoclusters & $\begin{array}{l}\text { Prevention of viral } \\
\text { proliferation } \\
\text { in vitro cells }\end{array}$ & PEDV & Pig & $46 \mu \mathrm{g} / \mathrm{ml}$ \\
\hline
\end{tabular}

navirus remains on surfaces for about $12 \mathrm{~h}$, silver-based coatings could neutralize them [54]. Various approved silver-based biocides need to be tested for SARS-CoV-2. Silver nanocompounds loaded on graphene oxide (GO) show promising results against enveloped and non-enveloped viruses [82, 83]. Facial masks based on the silver-nanocluster/silica composite present a vital impact against SARS-CoV-2 and could be used with metal, ceramic, and glass surfaces, indicating its beneficence in public places such as schools, hospitals, and supermarkets [84, 85]. Table 3 lists a variety of metal NP/hybrid structures used against SARSCoV-2. Fig. 6 shows the role of nanomedicine and replication cycle in neutralizing virus-based diseases like SARS-CoV-2. It is as a common RNA virus family (Fig. 6 ) divided into four classes- $\alpha, \beta, \gamma$, and $\delta$. It also possesses a genetic material formed as a single-stranded RNA with a capsid of the virus enclosed with club-shaped protein spikes and a virus genome on the surface [54].

The most important reasons for the spread of COVID-19 are faceto-face interaction and the resulting respiratory droplets of the diseased person. Nano-based gloves, personal protective equipment (PPE) kits, lab coats, and facemasks supply antimicrobial, hydrophobic, and fabrics against this virus (Fig. 7) [86]. Bhattacharjee et al. [87] used graphene and silver NPs to improve the antimicrobial activity of PPE textiles. The application of graphene in a textile enhances its mechanical properties, antimicrobial activity, resistance to flame, and flexibility. Campos et al. [86] illustrated the employment of masks with nanocoatings for im- 


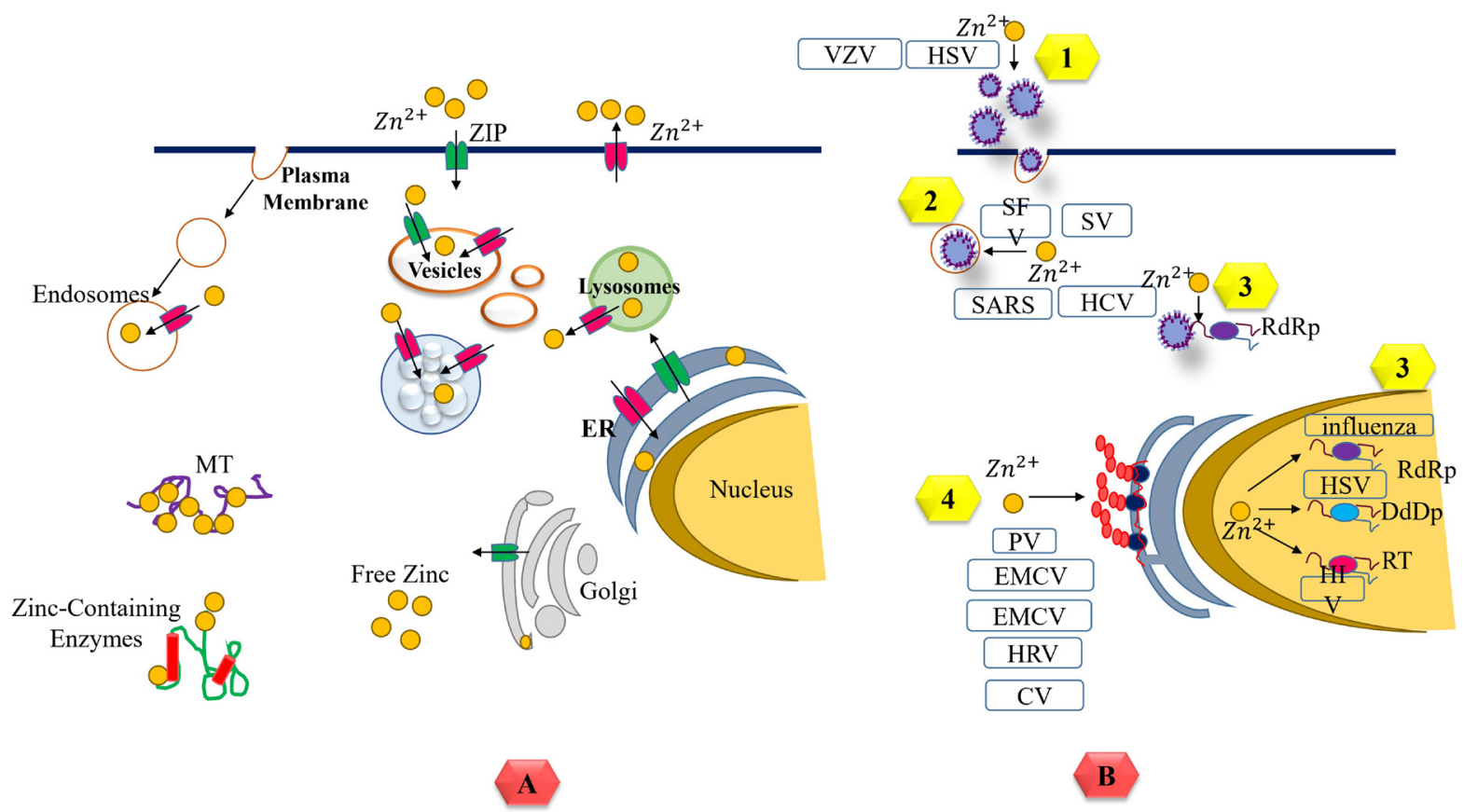

Fig. 8. Subcellular localization and transfer of zinc (A), Prevention of viral replication by zinc (B).

proved protection against viruses, as they do not damage the breathability and hydrophobicity of the textile. Silver NPs can be used in different textiles, including cellulose-based textiles, polyamide, polyester, and cotton, to enhance their filterability and antimicrobial activity. Doublelayered coatings, including silver and silica composite nanocoatings, can efficiently protect individuals from SARS-CoV-2. Additionally, non-irritating and environmentally-friendly sanitizers and disinfectant solutions based on the silver NPs for fighting against SARS-CoV-2 have been presented. These sanitizers provide efficient antifungal, antibacterial and antiviral activities. Positively charged silver NPs accompanied with non-migratory quaternary ammonium cations incorporated in a polymer matrix could also be utilized for the fabrication of antimicrobial coatings, which repel water and oil as well as inactivating SARS-CoV-2. Silver NPs could prevent virus replication and deactivate SARS-CoV-2 [88]. Moreover, silver NPs are used for coating medical devices composed of stainless steel $[89,90]$.

\subsection{Zinc nanocompounds}

Zinc $(\mathrm{Zn})$ is a vital element in cell proliferation, signaling, oxidative stress, differentiation, and immune activity, as well as a variety of alternative cellular procedures [91, 92]. Zn homeostasis greatly affects the Table 4.

The effect of zinc, zinc ionophores, and zinc conjugates on various respiratory viruses.

\begin{tabular}{|c|c|c|c|}
\hline Virus & Strain & Mechanism of action & Zinc formula \\
\hline \multirow[t]{2}{*}{ Influenza } & Influenza A & $\begin{array}{l}\text { Decreased viral-triggered DNA } \\
\text { fragmentation \& caspase-3 } \\
\text { activity }\end{array}$ & $\mathrm{ZnSO}_{4}$ \\
\hline & H1N1 & $\begin{array}{l}\text { Decreased virus titer post-in- } \\
\text { fection }\end{array}$ & $\begin{array}{l}\text { PEGylated } \mathrm{ZnO}- \\
\text {-NPs/ZnO-NPs }\end{array}$ \\
\hline \multirow{4}{*}{ Coronaviruses } & \multirow{4}{*}{ SARS-CoV } & Prevention of $3 \mathrm{CL}^{\mathrm{pro}}$ activity & $\begin{array}{l}\mathrm{Zn}^{2+} \text { ions/1-hy- } \\
\text { droxypyri- } \\
\text { dine-2-thione zinc }\end{array}$ \\
\hline & & Decreased viral replication & $\mathrm{ZnOAc}_{2} / \mathrm{PT}$ \\
\hline & & Prevention of $3 \mathrm{CL}^{\text {pro }}$ activity & $\begin{array}{l}\text { Zinc conjugated } \\
\text { TDT }\end{array}$ \\
\hline & & $\begin{array}{l}\text { Prevented RNA synthesis, RdRp } \\
\text { activity \& template binding }\end{array}$ & $\mathrm{ZnOAc}_{2}$ \\
\hline
\end{tabular}

immune system regarding its effective performance. It is an essential component of the signaling pathways associated with controlling the adaptive and innate immune responses [91, 93]. Consequently, $\mathrm{Zn}$ supplements are used to promote the immune system [94].

$\mathrm{Zn}$, with its potent immunogenic characteristics, binds to a variety of proteins, regulating their function. It has also been utilized in managing viral infection of coronavirus. $\mathrm{Zn}$ affects protein synthesis and activity, viral replication, RNA polymerase, and membrane fusion [95-98]. Table 4 provides a list of the effect of $\mathrm{Zn}$ on various respiratory viruses. Clinical trials have shown that $\mathrm{Zn}$ supplementation provides less serious and decreased symptoms period as well as diminished recurrent infections in viral diseases [95]. Regardless of the advantages of $\mathrm{Zn}$ in antiviral treatment, the type of infection associated with the redox species, formulation, and concentration of $\mathrm{Zn}$ is crucial. $\mathrm{Zn}$ has many immune health benefits as well as being available, affordable, and safe [94].

Experiments performed in vitro presented that $\mathrm{Zn}^{2+}$ provides antiviral function via preventing SARSCoV RNA polymerase, which might highlight the therapeutic efficacy of chloroquine acting as zinc ionophore. $\mathrm{Zn}^{2+}$ could also reduce the function of ACE2, which is the SARSCoV2 receptor. Enhanced antiviral immunity of zinc can also happen by the upregulation of interferon $\alpha$ output and rising its antiviral function. Zn has anti-inflammatory activity through preventing $\mathrm{NF \kappa B}$ signaling and regulation of regulatory Tcell functions that might decrease the cytokine storm in COVID19. Zn not only has a protective influence but also has a preventive effect for controlling COVID19 by limiting inflammation, inhibiting ventilator-caused lung damage, enhancement of mucociliary clearance, as well as regulating antibacterial and antiviral immunity. Zinc deficiency may cause the production of toxin bacteria and enteroviral pathogens, which trigger adenylate and guanylate cyclases, increase chloride secretion, lead to diarrhea, and reduce nutrient absorption. Chronic deficiency leads to the formation of pro-inflammatory cytokines, causing increased metabolic, inflammatory, immune, and neurodegenerative diseases [99]. Previously, zinc was proposed as a promising element for supporting the immune system and preventing H1N1 influenza [100]. $\mathrm{Zn}^{2+}$ cations in combination with $\mathrm{Zn}$ ionophore pyrithione have been presented as inhibitory agents for SARS-CoV RNA polymerase activity through reducing its replication 


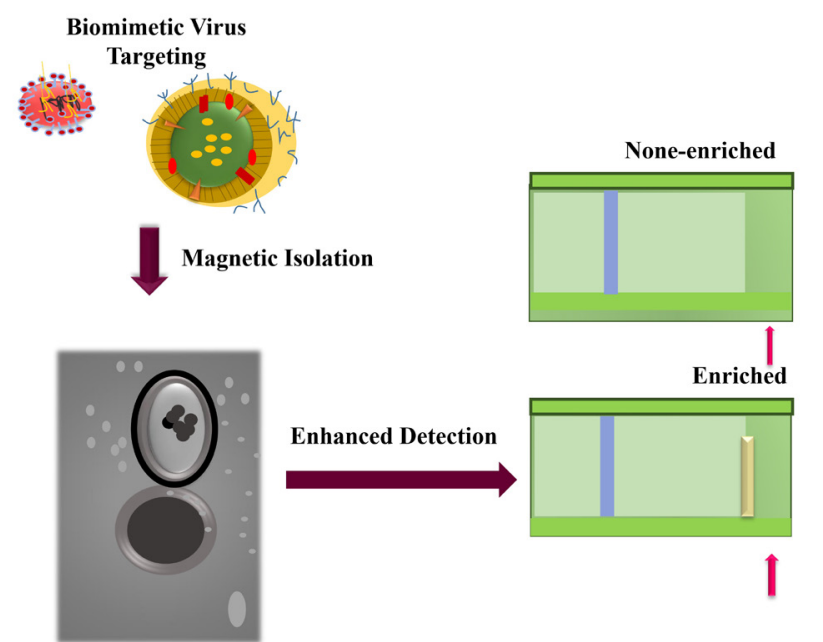

Fig. 9. Magnetic NPs mimic the cell membrane of the viral host.
Virus Capture

[96]. Some trials have shown the effect of chloroquine antiviral activity for treating COVID-19 [101]. Chloroquine is a zinc ionophore enhancing $\mathrm{Zn}^{2+}$ flux into the cell, and it is believed that growing intracellular $\mathrm{Zn}^{2+}$ concentration through chloroquine can arbitrate its antiviral impact against SARS-CoV-2. An alternative method for modulating COVID-19 via $\mathrm{Zn}$-based components includes aiming $\mathrm{Zn}$ ions in the viral proteins, as it has been demonstrated that disulfiram-triggered $\mathrm{Zn}^{2+}$ release from protease in MERS-CoV and SARS-CoV causes protein destabilization [102]. In this regard, Zn-based drugs including disulfiram can be used as promising antiviral agents for targeted oxidation of SARS-CoV-2. SARS-CoV-2 needs ACE2 to enter the target cells. Thus, regulation of ACE2 receptor is a potential approach for COVID-19 treatment [103105]. Speth et al. [106] illustrated that exposure to zinc $(100 \mu \mathrm{M})$ reduces recombinant human ACE-2 activity. Thus, zinc might enhance the dysfunction caused by nCoV-2019 in mucociliary clearance. Zinc significantly affects viral infections by modulating viral particle entrance, replication, and viral protein translation for various viruses [107]. Furthermore, Laurini et al. obtained the results achieved via mutating in the $14 \mathrm{~S}$-protein receptor binding domain (S-RBDCoV-2) residues and in silico the 18 ACE2 residues which chip in the binding interface of receptor/viral protein. Desirably, many significant mis-sense changes were anticipated for the enhancement of ACE2/S-RBDCoV-2 binding, such as the variants Y505W, N501T, Q493K, F456K/W, and L455D/W on S-RBDCoV-2 and R393K, R357K, L79I/W, Q42K, E35D, H34S7T/K, $\mathrm{D} 30 \mathrm{E}, \mathrm{T} 27 \mathrm{D} / \mathrm{K} / \mathrm{W}$, and Q24T on ACE2, respectively [108].

Zinc largely enhances cilia morphology [109] and improves ciliary beat number [110]. Therefore $\mathrm{Zn}$ enhances mucociliary clearance and virus or bacteria removal. Zn enlarges the barrier activity of the viruses through modifying close junction proteins ZO-1 and claudin-1 and boosting the antioxidant function of respiratory epithelia. Furthermore, COVID-19 has been demonstrated to damage mucociliary clearance and prompt the lung for additional bacterial and viral damage. Moreover, zinc may present antiviral activity by preventing RdRp and stopping viral RNA replication [100]. Modification of antiviral immunity via zinc might control SARS-CoV-2 disease by regulating IFN $\alpha$ production and boosting the antiviral activity, adjusted by IFN $\alpha$-stimulated JAK/STAT signaling and upregulation of PKR and RnaseL antiviral proteins, which can corrupt viral RNA and prohibit its translation [111]. Cytokine storm highly affects the pathogenesis of COVID-19 [112], while zinc, with its anti-inflammatory activity via prohibiting $\mathrm{I} k \mathrm{~B}$ kinase (IKK) activity and NF- $\kappa \mathrm{B}$ signaling as well as regulating T-cell functions, down-regulates the formation of pro-inflammatory cytokine [113, 114]. Additionally, zinc could control risk factors of COVID-19-caused fatality rate as immune deficiency, aging, and metabolic diseases (e.g., atherosclerosis, diabetes, and obesity) are believed to be risk factors for elevated fatality as well as zinc deficiency [115-117]. Having said this, Zn might provide an advantageous influence on limiting the mentioned risk factors [107, 118]. Fig. 8 depicts subcellular localization and transfer of zinc as well as prevention of viral replication by zinc.

Additionally, zinc prevents viral attachment to the mucosal cells and the replication of SARS-CoV and respiratory syncytial virus via by forming antiviral interferon (IFN)- $\alpha$ and IFN- $\gamma$ [96, 118, 119]. As SARS-CoV-2 binds to the cell surface ACE2 by its spike proteins to start viral replication and transcription, zinc could decrease SIRT-1-regulated ACE2 expression [120, 121]. In this way, Lee et al. [122] have reported that human lung cells modified with zinc and emetine or triclabendazole inhibit ACE2 expression with no traces of cytotoxicity. In another study, Carlucci et al. [123] reported that zinc sulfate, hydroxychloroquine, and azithromycin present superior advantages for treating patients with COVID-19 compared to those receiving only hydroxychloroquine and azithromycin such as improved rates of hospital discharge as well as decreased fatality. Another recent in vitro research conducted by Chen et al. [124] on human airway cells presented that azithromycin and zinc could hinder ACE2 expression, indicating the potential therapeutic and prophylactic effect of zinc for treating COVID-19.

\subsection{Magnetic nanocompounds}

Nanosensing based on magnetic materials is a newly-emerged subject in the field of biosensing. These days, magnetic materials are largely used in biomedical and biological areas. The most recent developments in nanotechnology and magnetic nanomaterials have turned diagnostic approaches to nanoscales as well as providing early-stage diagnosis $[101,125]$. Nanotechnology can enhance the targeting process of viruses on biological samples, including blood, throat, and nasal fluids, by implementing special virus receptors on the superficial area of magnetic nanomaterials. Due to the nano size of viruses, their behavior could be utilized to tailor structures similar to viruses for presenting gene modification and targeted drug delivery [126, 127].

Magnetic NPs could be guided in magnetic fields to target organs including the lungs prone to respiratory issues caused by viruses. Additionally, drug-loaded nanocarriers could be marked with viral antigen antibodies [80, 128]. In this manner, Zhao et al. [49] synthesized magnetic NPs with a coating of poly (amino ester)/carboxyl groups for SARS-CoV-2 detection and viral RNA extraction. Their results demonstrated that over $90 \%$ of the RNA were captivated using the pcMNPs during $10 \mathrm{~min}$. This easy method can refine viral RNA from alternative samples in $20 \mathrm{~min}$ through a facile method. In another study, Chen et al. [129] used magnetic NPs to split the virus particles. They presented that biomimetic NPs were used to improve detection by supplementing viruses. The NPs imitated the host cell membrane and were tailored with 


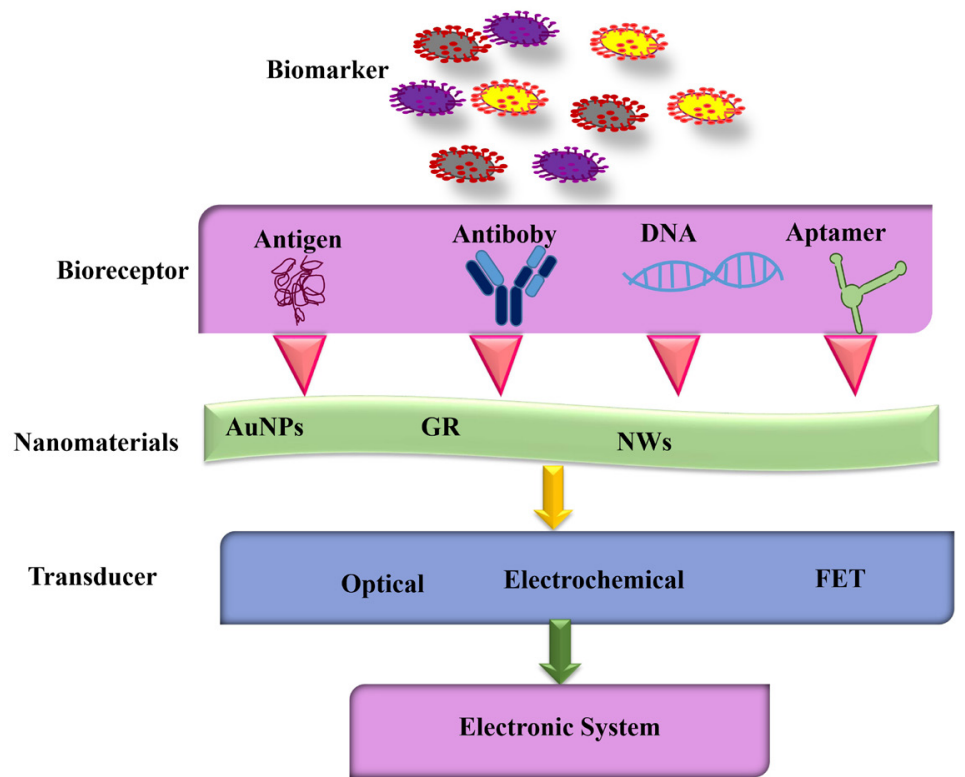

Fig. 10. Nanobiosensor for detecting coronavirus.

target receptors to provide virus-binding allowance to the NPs (Fig. 9).

Magnetic NPs were based on the encapsulation of superparamagnetic iron oxide nanoparticles (SPIONs), assisting the separation of NP-bound virus pathogen by a magnet.

\subsection{Carbon nanocompounds}

Carbon-based materials are novel materials that have been largely researched and employed in biological fields. Carbon nanotubes (CNTs) possess small dimensions between 10 and $100 \mathrm{~nm}$, great dimensionality (2D, 3D), and excellent light-heat conversion efficacy. Their chemical and physical properties, including high storage space in the internal tube and surface load power, provide convenient biological behaviors including suitable biocompatibility, excellent bioabsorption rate, elevated permeability, multiple-energy surface functional group, and targeted biomolecule treatment ability. The mentioned properties represent novel concepts for advancing modern drugs against coronaviruses. As CoVs are delicate to acids and elevated temperatures over $56{ }^{\circ} \mathrm{C}, \mathrm{CNTs}$ prepared by acidization and conjugated with special RNA lyase might be a promising material for inhibiting SARS-CoV-2 [130, 131].

Many researchers have reported the application of CNTs for diagnosing respiratory viruses such as SARS-CoV-2. For example, Yeh et al. [132] prepared a modern CNT size-tunable enrichment microdevice (CNT-STEM) with the ability to enrich and concentrate viruses. The avian influenza virus strain was determined by this tool. The CNT-STEM largely improves detection sensitivity and virus isolation rates [132, 133]. Due to the feasibility and credibility of this method, it could be tailored to identify SARS-CoV-2 proteins or RNA. In alternative research, a sensing method based on a single wall CNT (SWCNT) was used for COVID-19 detection. The prepared nanosensor composed of SWCNTs functionalized with ACE2 showed excellent binding attraction for the spike protein of SARS-CoV-2 and doubled the fluorescence signal when encountered with target viruses [134-136]. Another biosensor based on carbon nanomaterials with the ability of rapid COVID-19 antibodies detection was fabricated from $3 \mathrm{D}$ bio-printed electrodes joined with reduced-graphene-oxide (rGO) nanoflakes. Viral antigens that were immobilized on the rGO nanoflakes were utilized to identify targets. The selective binding of antibodies to the antigens in the device changed the electrical circuit's impedance [137]. Moreover, nanodiamonds are also promising material for the diagnosis of COVID-19 because of their low cytotoxicity and excellent stability. In a study, fluorescent nanodiamonds were employed to act as a high-sensitive mark for COVID-19 lateral flow immunoassay, which resulted in $10^{5}$ times more sensitivity compared with that of the usual GNP-based lateral flow test. The mentioned studies propose that nanocarbon-based materials could be utilized as antiviral treating agents against COVID-19 [138, 139]. Functionalized carbon nanocomposites by metallic or polymeric NPs via surface functional groups (e.g., hydroxyls, carboxylic acids, and lactones) could limit the spread of COVID-19. For example, conventional activated carbon powder could eliminate viruses trapping them in nanopores via a hydrophobic activity with the virus [140, 141]. The viral particle can interact with several kinds of carbon-based nanomaterials, including SWCNT, activated carbons, nanodiamonds (ND), carbon quantum dots (CQDs), multiwall carbon nanotubes (MWCNT), graphene, and GO. Their prospective usage for COVID-19 therapy is the removal of viruses from air and water via different valid approaches [142, 143].

\subsection{Graphene nanocompounds}

Graphene and GO materials, graphene-silver composites, and MXenes $\left(\mathrm{Ti}_{3} \mathrm{C}_{2} \mathrm{~T}_{\mathrm{x}}\right.$ ) are novel materials presenting antiviral and antibacterial activity [144]. Graphene and CNTs are the most favorable carbon-based nanomaterials for biosensors [145, 146]. Graphene has excellent mechanical, electrical, and thermal properties [147]. Graphene could also be readily functionalized by adding functional groups to its 2D plane due to its structure full of defects, which turns it into an appropriate base for ligand immobilization, including single-strand DNA and antibodies for preparing aptasensors and immunosensor [148-150]. Graphene is widely utilized for optical and electrochemical biosensors with high sensitivities [151]. Moreover, graphene and nanowires of $\mathrm{In}_{2} \mathrm{O}_{3}$ have been employed for the field-effect transistor (FET) to detect SARS-CoV and SARS-CoV-2 [152]. Fig. 10 illustrates a nanobiosensor for detecting coronavirus. Also, Fig. 11 demonstrates $\mathrm{In}_{2} \mathrm{O}_{3}$-nanowirebased FET immunosensor for SARS-CoV. This schematic image shows the nanowires with the covalent immobilization of the Fn probe. The $\mathrm{N}$-proteins were positively charged At the working $\mathrm{pH}=7.4$, and thus their binding on a p-type channel led to charge carrier (holes) and a final reduction of conductance. Bovine serum albumin (BSA) was utilized as a "blocking agent" for source-drain electrodes and nanowires, therefore preventing NSB, which may result in false-positive outcomes [153].

Graphene is additionally used in face masks or on surfaces in public places to sterilize them [76]. GO as well as rGO also present various applications in immunosensor [154]. Graphene oxide, a 2D monoatomic thin nanomaterial, presents a natural antiviral activity against the porcine epidemic diarrhea virus (PEDV) virus, largely higher compared with that of graphite oxide [155, 156]. Graphene oxide, being armed with the negative surface charge, makes a powerful bind with the positively charged viruses, which could disable virus activity [144, 157]. 


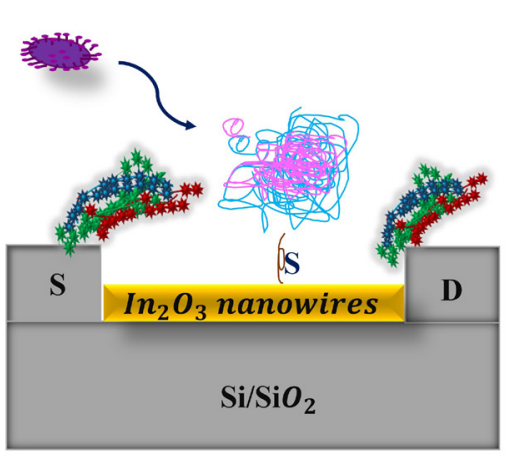

$\mathrm{Du}$ et al. [158] studied the antiviral function of hypericin-loaded GO. The antiviral efficiency of hypericin was enhanced due to the high loading capacity and low cytotoxicity of GO. The fabricated complex prevented viral replication via the virus inactivation and elimination of viral attachment to the host cell. In another study, Akhavan et al. [159] discovered that the composite film of graphene tungsten oxide inactivates viruses by irradiating it with visible light because of the photo-degradation of viral capsid protein and the viral RNA release. Graphene oxide has also exhibited antiviral function against the coronavirus of porcine epidemic diarrhea [160]. It can also be used for sterilizing facemasks and their re-use due to the electrical and thermal, and electrical characteristics of graphene, enabling filters and fabrics sterilization of the facemasks [161].

Seo et al. [162] have also prepared a new biosensor based on antibodies for detecting the S protein of SARS-CoV-2 from graphene sheets, which were covered with a SARS-CoV-2 antibody. The prepared sensor could distinguish between diseased and healthy people with a limit of detection (LOD) of $2.42 \times 10^{2}$ copies $/ \mathrm{mL}$. Ye et al. [160] have also tested the antiviral activity of a variety of graphene oxide-based antiviral agents against the PEDV and PRV viruses. Their results presented that the antiviral activity of GO and $\mathrm{rGO}$ was the highest among the other derivatives, including graphene oxide/polyvinylpyrrolidone composite and graphite oxide, while graphite and graphene oxide/poly(diallyl dimethylammonium chloride) composite did not present any antiviral activity.

\subsection{Quantum dot nanocompounds}

Quantum dots (QDs), also called "semiconductor nanomaterials" with the size range of 1 to $10 \mathrm{~nm}$, are novel fluorescent probes for molecular imaging in bio- and chemosensors, being extensively utilized for diagnosing COVID-19 due to their special properties such as optical characteristics [163, 164]. Moreover, the emission wavelength of QDs could be readily and accurately adjusted by altering their size [165]. For example, Ashiba et al. [166] proposed an extremely sensitive biosensor for detecting viruses and prohibiting the virus spread. The detection limit of the sensor was $0.01 \mathrm{ng} / \mathrm{mL}$ virus, equivalent to 100 viruses. In another study, Roh et al. [167] studied the sensitive and fast identification of SARS-CoV by a QD-conjugated RNA aptamer. The QD-conjugated RNA aptamer could particularly make a bind with the SARS-CoV N protein, which was immobilized to supply an optical signal. The results of this study indicated the detection limit of $0.1 \mathrm{pg} \mathrm{mL}^{-1}$, which might facilitate developing a sensitive diagnosis of COVID-19 [168].

Carbon quantum dots (CQDs) show promising results in imparting with viruses and inhibiting virus entrance to the host cells. It has recently been presented that CQDs associated with boronic acid ligands intervene in the activity of the S-coronavirus protein and greatly prohibit its entrance to the host cells, and the addition of CQDs to cell culture either before or after human coronavirus infection largely decreases cell infection rate [169]. As QDs present a key role in treating human CoVs infections, many pieces of research have been performed in this man-
Fig. 11. $\mathrm{In}_{2} \mathrm{O}_{3}$-based FET immunosensor for SARS-CoV detection.

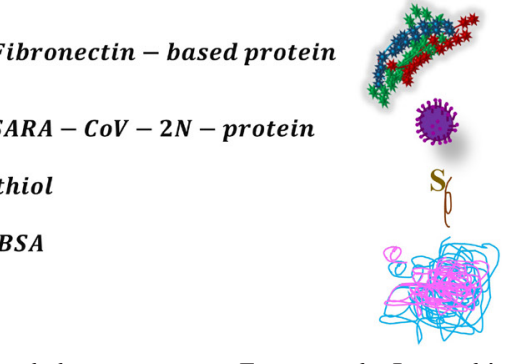

ner. For example, Loczechin et al. [170], studied the antiviral activity of seven different CQDs were studied for curing CoV HCoV-229E. Using the QD therapy, concentration-based virus inactivation was obtained. Because of the CQDs' interaction with the HCoV-229E receptors, the HCoV-229E blockage in host cells occurs. Moreover, the replication phase of viruses was also prevented [142].

In another study, Ahmed et al. [171] prepared chiral zirconium QDs for detecting coronavirus. Zirconium QDs and magnetic NPs conjugated with coronavirus antibodies could attach to the virus-based target and generate magneto plasmonic-fluorescent nanohybrids, able to be divided using a magnet with a detection limit of 79.15 EID/50 $\mu$ l. Additional$1 y$, in another study, the same authors fabricated a chiro-immunosensor capable of detecting coronavirus infection in blood via self-assembled chiroplasmonic GNPs and QDs. Non-symmetric plasmonic chiral GNPs formed by self-assembly increased the spectral extent of CD response, which caused an enhanced plasmonic resonant coupling with an excited state of QDs. The chiro-immunosensor presented the detection limit of 47.91 EID/50 $\mu$ for coronavirus [172]. Furthermore, Du et al. [173] fabricated $\mathrm{Ag}_{2} \mathrm{~S}$ QDs functionalized with glutathione with convenient chemical stability and excellent optical properties to prevent coronavirus (PEDV) proliferation. The results presented that using Vero cells, a concentration of $46 \mu \mathrm{g} / \mathrm{mL}$ for $\mathrm{Ag}_{2} \mathrm{~S}$ QDs provided over $90 \%$ viability, accompanied with the PEDV N protein expression, which was down-regulated in a concentration-dependent state. The authors concluded that $\mathrm{Ag}_{2} \mathrm{~S}$ QDs prevent viral proliferation by blocking RNA synthesis of viruses.

\subsection{Liposomes nanocompounds}

Lipid-based NPs are composed of lipid bilayer vesicles used for encapsulating drugs and transporting hydrophilic and lipophilic drugs due to their controllable biological behavior, compatibility, excellent stability, low toxicity, efficient transport within biosystems, and facile scaling-up. Micelles, microspheres, dendrimers, bilayers, and liposomes are examples of lipid-based nanomaterials [174]. Liposome NPs, in particular, are widely utilized in the modern delivery of antiviral drugs, including acyclovir, zidovudine, and efavirenz, and show great potential in drug delivery to the lungs for respiratory disease therapy of COVID-19, tuberculosis, and pneumonia [175-177]. Liposome NPs have also been evaluated as hopeful viral vaccines [178]. These NPs could be employed by inhalation, oral use, or intravenous. Liposomes, common DDS for pulmonary drug delivery, are inherent in lungs and present beneficial characteristics such as the ability to incorporate drugs within their membrane bilayer or in their core, capacity to reduce the toxicity of drugs, altering the pharmacokinetics of drugs, making them a suitable drug nanocarrier for treating pulmonary infections. Liposomal DDS has been used to treat lung infections via the inhalation approach [179].

Encapsulated antiviral vaccines and agents in the cell membrane could be performed using functionalized liposomal and micellar formulations [180]. Tai et al. [181] demonstrated that the liposomal composi- 


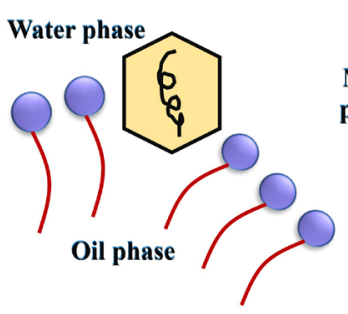

A. Adsorption of template Virus the micelle
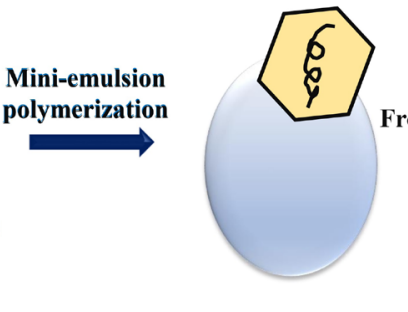

B. Molecular imprinting occurs on The surface of nanoparticles
Fig. 12. Schematic illustration of polymeric virus catchers prepared by molecular imprinting techniques. tion of hydroxychloroquine could be more efficient through the inhalation approach relative to the oral and injection approaches for limiting COVID-19. It was deducted that the inhalable liposomes, including hydroxychloroquine, might present clinical advantages for treating COVID-19. Additionally, Feliciello et al. [182] illustrated that the pulmonary proteoliposome could decrease the virus amount in the lung and assist the immune function to limit lung infection.

The functionalized liposome, stealth liposome, is biocompatible and biodegradable and provides stimulus-responsive, extended systemic circulation and targeted drug delivery. It is one of the options for formulating novel treatments for COVID-19 infection [54].

These non-viral transmission systems decrease carcinogenesis and immunogenicity and present appropriate display promising benefits including limited toxicity, effective contact with lipid cell membranes, and improved endosomal escape. As the nuclear transmission of IFN regulatory factor 3 is eliminated by coronaviruses, interferon loading into the nanoliposomes could provide a supporting impact on SARS-CoV2 disease [183, 184]

Liposomes are capsules with an exterior phospholipid bilayer and an

Table 5.

Nanoparticle-based tools against respiratory viruses.

\begin{tabular}{|c|c|c|c|c|c|c|}
\hline $\begin{array}{l}\text { Types of substances used } \\
\text { for fabrication }\end{array}$ & Types of virus & Antigen/epitope & Adjuvant & $\begin{array}{l}\text { Mean diameter } \\
(\mathbf{n m})\end{array}$ & Achievements & Ref. \\
\hline \multicolumn{7}{|c|}{ Polymeric-based nanostructured materials } \\
\hline Polyanhydride & RSV & $\mathrm{G}$ and $\mathrm{F}$ glycoproteins & - & $200-800$ & $\begin{array}{l}\text { Vaccinated mice were greatly protected against } \\
\text { virus replication in the lungs }\end{array}$ & {$[196]$} \\
\hline \multirow[t]{3}{*}{ HPMA/NIPAM $\dagger$} & RSV & $\mathrm{F}$ protein & $\begin{array}{l}\text { TLR-7/8 } \\
\text { agonist }\end{array}$ & $12-25$ & $\begin{array}{l}\text { NPs presented good antigenicity and demon- } \\
\text { strated excellent titers of TH1 isotype anti-RSV } \\
\text { F antibodies followed by vaccination }\end{array}$ & {$[197]$} \\
\hline & $\mathrm{IF}(\mathrm{H} 1 \mathrm{~N} 1)$ & Antigen M2e & $\begin{array}{l}\text { Heat shock } \\
\text { protein } 70^{\circ} \mathrm{C}\end{array}$ & $200-250$ & $\begin{array}{l}\text { NPs enhanced pharmacokinetic profile and in- } \\
\text { creased vaccine immunogenicity for stimulating } \\
\text { T cell immunity and antibodies }\end{array}$ & {$[198]$} \\
\hline & $\begin{array}{l}\text { Swine IF } \\
(\mathrm{H} 1 \mathrm{~N} 2)\end{array}$ & Killed Swine IF & - & 571.7 & $\begin{array}{l}\text { Intranasal immunization of mice with prepared } \\
\text { NPs directed immune response to a more effi- } \\
\text { cient quality profile }\end{array}$ & {$[199]$} \\
\hline \multirow[t]{3}{*}{ Chitosan } & $\mathrm{IF}(\mathrm{H} 1 \mathrm{~N} 1)$ & HA-Split & - & $300-350$ & $\begin{array}{l}\text { Nanovaccine illustrated potent mucosal IgA and } \\
\text { cellular immune responses in the respiratory } \\
\text { path that caused decreased lung virus titers and } \\
\text { nasal viral shedding }\end{array}$ & {$[200]$} \\
\hline & IF(H1N1) & Antigen of H1N1 & - & 140 & $\begin{array}{l}\text { Nanovaccine decreased mortality and conferred } \\
\text { total protection for the vaccinated mice against } \\
\text { lethal IF virus }\end{array}$ & {$[201]$} \\
\hline & IF(H1N1) & Hemagglutinin & - & $100-200$ & $\begin{array}{l}\text { After three nasal immunizations, the nanovac- } \\
\text { cine triggered elevated grades of mucosal sIgA } \\
\text { and serum IgG }\end{array}$ & {$[202]$} \\
\hline \multirow[t]{2}{*}{ PLGA $\ddagger$} & $\begin{array}{l}\text { Swine IF } \\
(\mathrm{H} 1 \mathrm{~N} 2)\end{array}$ & Inactivated $\mathrm{H} 1 \mathrm{~N} 2$ virus & - & $200-300$ & $\begin{array}{l}\text { Subcutaneous immunization with prepared vac- } \\
\text { cine improved the supporting immune responses } \\
\text { against IF virus in mice }\end{array}$ & {$[203]$} \\
\hline & BPI3V & BPI3V Proteins & - & 225.4 & $\begin{array}{l}\text { Nanovaccine decreased virus-based antigenic } \\
\text { load and lung pathology in the lung }\end{array}$ & {$[204]$} \\
\hline
\end{tabular}

interior hydrophilic core, which contains therapeutic agents. Liposomes supply effective encapsulation of the conjugated species and facile adjustment to improve their cellular and mucosal uptake [185]. It has also been demonstrated that encapsulating Ara-AMP, ACV, and IFN in liposomes improves the efficiency of antiviral drugs and decreases their toxicity, side effects, and dosage. The antiviral function of IFN-liposomes is thirteen times higher than that of the free one. Therefore, the application of liposomes for encapsulating antiviral drugs is a powerful method for improving their efficiency [186].

\subsection{Polymeric nanocompounds}

Nowadays, polymeric NPs have gained much attention among scientists because of their special encapsulation and optical properties for the diagnosis, prevention, and treatment of a variety of virus-based diseases including HIV, HSV, influenza, and Ebola. Polymeric NPs have been used as SVLPs for stimulating immune cell interaction and antigen procedures against $\mathrm{CoV}$ diseases [187]. The nano polymeric vaccines are durable against DNAse and could be employed in vivo for vaccines. Intranasal application of targeted nanopolymers associated with 
anti-CD40 DC maturation stimuli could improve the mucosal IgA and systemic level of IgG to fight N protein of SARS-CoV. Nevertheless, systemic and mucosal immune responses were not determined for plain pDNA. Sun et al. [188] demonstrated intramuscular application of chitosan-encapsulated $\mathrm{N}$ protein of bovine $\mathrm{CoV}(\mathrm{BCV} \mathrm{N}) \mathrm{NPs}$ could greatly improve IgG, and IgA amounts relative to Montanide ISA 206, presenting the efficiency of chitosan NPs as an adjunct for BCV N protein.

Intranasal delivery of antigens encapsulated with polymer provides a powerful immune activity, and vaccination outcome depends on polymer and antigen properties [189]. The advent of new nanomaterials for enhancing the efficiency of COVID-19 therapy depends on the preparation of polymeric NPs possessing fast and great mucus penetration as well as the advent of non-toxic, stable, and biodegradable NPs with low pulmonary toxicity in the lung. Surface treatment of the NPs using PEG conjugation acting as a capping agent and targeting moieties to limit side effects are also crucial. Polymer-based nanocompounds are promising against COVID-19 due to their safety profile, appropriate biodegradability and biocompatibility, easy synthesis, prevention in degradation of encapsulated drugs, and the ability to be prepared in desired sizes, shapes, and characteristics [190]. PEG and PLGA are two types of polymers approved by the FDA that could be used against COVID-19 owing to their excellent biodegradability and biocompatibility $[191,192]$. One disadvantage of polymeric NPs is their rapid absorption by the reticuloendothelial system, which can be treated using surface modification through PEG [193]. In this regard, Sankarakumar et al. [194] prepared virus catchers out of polymer by molecular imprinting method, which is a rapid, low-cost, stable, and secure process for anti-viral treatment. In the first step, nanoparticles were synthesized by a hydrophobic crosslinker ethylene glycol dimethacrylate (EGDMA) combination with various functional monomers with a molar ratio of 1:4. Virus imprinted nanoparticles (vMIPs) were prepared via adding the full viral template virus (fr phages) into the monomer phase former to the polymerization phase. Non-imprinted particles (NIPs) were obtained without adding the template virus and were utilized as limitations in whole steps. The system of one-stage miniemulsion polymerization for virus surface imprinting is indicated in (Fig. 12).

Lin et al. [195] have also prepared a new vaccine from synthetic biodegradable DEPE-PEG and PLGA nanopolymers for delivering STING (stimulator of interferon genes) agonists and viral antigens for treating MERS-CoV. The prepared hollow-shaped polymeric nanocompound lowered systemic reactogenicity, was $\mathrm{pH}$-responsive during the release, and presented eminent local immune function. The findings of this research showed that this approach simplifies the development of safe and efficient vaccines in fighting against viral pathogens. Table 5 lists nanoparticle-based tools against respiratory viruses.

The polymeric nanoparticles are used due to their high yield of encapsulation and also controlling the release of drugs and vaccine adjuvants by low associated toxicities. Lee et al. [80] introduced the polymer-templated protein with the ability to orient to hemagglutinin1 of influenza virus and increase the immunogenicity of mice. Regarding VLPs, this structure has some advantages such as do not need using intricate genetic techniques, affordable and straightforward approach.

\section{Conclusions and future insights}

COVID-19 is a new global health issue, which has influenced over 200 countries after its outbreak in Wuhan City, China. COVID-19 was announced as a pandemic by the WHO on 11 March 2020. COVID-19 emerges in individuals through the entrance of the virus into the epithelial cells of the human lung. The genome of COVID-19 has included $\sim 30000$ nucleotides. It has been encoded via four structural proteins, in- cluding Envelop (E) protein, Spike (S) protein, Membrane (M) protein, and Nucleocapsid $(\mathrm{N})$ protein. Nowadays, nanotechnology has largely contributed to the fight against this pandemic by mitigating infection for the diagnosis, prevention, and treatment of COVID-19. The advent of nanomaterials for virus-based disease encompasses preventive steps, diagnostic methods, nanosensors, and therapeutic approaches or vaccines to transmit antiviral agents into the human body. Moreover, the similar scale of NPs and viruses enables them to replicate the functional and structural properties of viruses. Therefore, nanomaterials could be the best substitute for developing vaccines. These are definitely due to the broad drug payloads, adjustable surface charge of the particle with the possibility of encapsulation, large surface area to volume ratio (increased solubility in comparison with larger particles), and particle size (that impacts circulation time and bioavailability) which can be fitted. These characteristics make nanoparticulate drug delivery systems desirable candidates improve and/or achieve therapeutic impacts and can be considered for future aspects which are despite similar bulk composites. A wide variety of NPs, including silver, gold, zinc, graphene, carbon, liposomes, and polymeric compounds, have shown promise antiviral activity and can be used in vaccine development, therapeutics, nanosensors, and for diagnostic purposes. For instance, silver has presented antibacterial, antifungal, anti-angiogenesis, antiplatelet, anti-inflammatory, and anti-cancer properties. In addition, AuNPs are widely utilized in nano vaccines due to their beneficial properties, such as providing immunization and carrying antigens [61]. Clinical trials have shown that $\mathrm{Zn}$ supplementation provides less serious and decreased symptoms period as well as diminished recurrent infections in viral diseases [95]. Zn has many immune health benefits as well as being available, affordable, and safe [94]. Furthermore, CNTs possess small dimensions between 10 and $100 \mathrm{~nm}$, great dimensionality (2D, 3D), and excellent light-heat conversion efficacy. Their chemical and physical properties, including high storage space in the internal tube and surface load power, provide convenient biological behaviors including suitable biocompatibility, excellent bio-absorption rate, elevated permeability, multiple-energy surface functional group, and targeted biomolecule treatment ability that can be applied as a promising material to future manufacturing biomaterial. Also, lipid-based NPs are composed of lipid bilayer vesicles used for encapsulating drugs and transporting hydrophilic and lipophilic drugs due to their controllable biological behavior, compatibility, excellent stability, low toxicity, efficient transport within biosystems, and facile scaling-up. The nano polymeric vaccines are durable against DNAse and could be employed in vivo for vaccines. Intranasal application of targeted nanopolymers associated with anti-CD40 DC maturation stimuli could improve the mucosal IgA and systemic level of IgG to fight $\mathrm{N}$ protein of SARS-CoV.

\section{REFERENCES}

[1] W.H. Organization, World Health Organization coronavirus disease (COVID-19) dashboard, World Health Organization (2020).

[2] M.A. Shereen, S. Khan, A. Kazmi, N. Bashir, R. Siddique, COVID-19 infection: Origin, transmission, and characteristics of human coronaviruses, Journal of advanced research 24 (2020) 91

[3] F. Li, Structure, function, and evolution of coronavirus spike proteins, Annual review of virology 3 (2016) 237-261.

[4] E. Serag, M. El-Zeftawy, Environmental aspect and applications of nanotechnology to eliminate COVID-19 epidemiology risk, Nanotechnology for Environmental Engineering 6(1) (2021) 1-17

[5] P. Singh, D. Singh, P. Sa, P. Mohapatra, A. Khuntia, S. K Sahoo, Insights from nanotechnology in COVID-19: prevention, detection, therapy and immunomodulation, Nanomedicine 16(14) (2021) 1219-1235.

[6] S. Boopathi, A.B. Poma, P. Kolandaivel, Novel 2019 coronavirus structure, mechanism of action, antiviral drug promises and rule out against its treatment, Journal of Biomolecular Structure and Dynamics 39(9) (2021) 3409-3418.

[7] K. Sheikhi, H. Shirzadfar, M. Sheikhi, A review on novel coronavirus (Covid-19): symptoms, transmission and diagnosis tests, Research in Infectious 
Diseases and Tropical Medicine 2(1) (2020) 1-8

[8] L. Singh, H.G. Kruger, G.E. Maguire, T. Govender, R. Parboosing, The role of nanotechnology in the treatment of viral infections, Therapeutic advances in infectious disease 4(4) (2017) 105-131

[9] D. Yang, Application of Nanotechnology in the COVID-19 Pandemic, International Journal of Nanomedicine 16 (2021) 623

[10] H.R. Rezaie, H.B. Rizi, M.M.R. Khamseh, A. Öchsner, Primary Information About Biomaterials, A Review on Dental Materials, Springer2020, pp. 1-30.

[11] M. Radmansouri, E. Bahmani, E. Sarikhani, K. Rahmani, F. Sharifianjazi, M. Irani, Doxorubicin hydrochloride-Loaded electrospun chitosan/cobalt ferrite/titanium oxide nanofibers for hyperthermic tumor cell treatment and controlled drug release, International journal of biological macromolecules 116 (2018) 378-384.

[12] S.P. Adhikari, S. Meng, Y.-J. Wu, Y.-P. Mao, R.-X. Ye, Q.-Z. Wang, C. Sun, S. Sylvia, S. Rozelle, H. Raat, Epidemiology, causes, clinical manifestation and diagnosis, prevention and control of coronavirus disease (COVID-19) during the early outbreak period: a scoping review, Infectious diseases of poverty 9 (1) (2020) 1-12 [13] B. Saawarn, S. Hait, Occurrence, fate and removal of SARS-CoV-2 in wastewater: Current knowledge and future perspectives, Journal of Environmental Chemical Engineering 9(1) (2021) 104870.

[14] Y. Yang, W. Shang, X. Rao, Facing the COVID-19 outbreak: What should we know and what could we do?, Journal of medical virology (2020)

[15] D. Wu, T. Wu, Q. Liu, Z. Yang, The SARS-CoV-2 outbreak: what we know, International Journal of Infectious Diseases 94 (2020) 44-48.

[16] M. Pal, G. Berhanu, C. Desalegn, V. Kandi, Severe acute respiratory syndrome coronavirus-2 (SARS-CoV-2): an update, Cureus 12(3) (2020).

[17] L. Mousavizadeh, S. Ghasemi, Genotype and phenotype of COVID-19: Their roles in pathogenesis, Journal of Microbiology, Immunology and Infection 54(2) (2021) 159-163.

[18] A.D. Elmezayen, A. Al-Obaidi, A.T. Şahin, K. Yelekçi, Drug repurposing for coronavirus (COVID-19): in silico screening of known drugs against coronavirus $3 \mathrm{CL}$ hydrolase and protease enzymes, Journal of Biomolecular Structure and Dynamics 39(8) (2021) 2980-2992.

[19] J.S. Mani, J.B. Johnson, J.C. Steel, D.A. Broszczak, P.M. Neilsen, K.B. Walsh, M. Naiker, Natural product-derived phytochemicals as potential agents against coronaviruses: A review, Virus research 284 (2020) 197989.

[20] M.K. Gupta, S. Vemula, R. Donde, G. Gouda, L. Behera, R. Vadde, In-silico approaches to detect inhibitors of the human severe acute respiratory syndrome coronavirus envelope protein ion channel, Journal of Biomolecular Structure and Dynamics 39(7) (2021) 2617-2627

[21] R.J. Khan, R.K. Jha, G.M. Amera, M. Jain, E. Singh, A. Pathak, R.P. Singh, J. Muthukumaran, A.K. Singh, Targeting SARS-CoV-2: A systematic drug repurposing approach to identify promising inhibitors against $3 \mathrm{C}$-like proteinase and 2'-O-ribose methyltransferase, Journal of Biomolecular Structure and Dynamics 39(8) (2021) 2679-2692.

[22] S.A. Khan, K. Zia, S. Ashraf, R. Uddin, Z. Ul-Haq, Identification of chymotrypsin-like protease inhibitors of SARS-CoV-2 via integrated computational approach, Journal of Biomolecular Structure and Dynamics 39(7) (2021) 2607-2616. [23] T. Pillaiyar, M. Manickam, V. Namasivayam, Y. Hayashi, S.-H. Jung, An overview of severe acute respiratory syndrome-coronavirus (SARS-CoV) 3CL protease inhibitors: peptidomimetics and small molecule chemotherapy, Journal of medicinal chemistry 59(14) (2016) 6595-6628.

[24] P. Sarma, N. Shekhar, M. Prajapat, P. Avti, H. Kaur, S. Kumar, S. Singh, H. Kumar, A. Prakash, D.P. Dhibar, In-silico homology assisted identification of inhibitor of RNA binding against 2019-nCoV N-protein (N terminal domain), Journal of Biomolecular Structure and Dynamics 39(8) (2021) 2724-2732.

[25] M. Pal, G. Berhanu, C. Desalegn, V. Kandi, Severe Acute Respiratory Syndrome Coronavirus-2 (SARS-CoV-2): An Update, Cureus 12(3) (2020) e7423-e7423.

[26] I.M. Artika, A.K. Dewantari, A. Wiyatno, Molecular biology of coronaviruses: current knowledge, Heliyon 6(8) (2020) e04743

[27] I. Astuti, Ysrafil, Severe Acute Respiratory Syndrome Coronavirus 2 (SARSCoV-2): An overview of viral structure and host response, Diabetes Metab Syndr 14(4) (2020) 407-412.

[28] S.K. Saxena, S. Kumar, P. Baxi, N. Srivastava, B. Puri, R. Ratho, Chasing COVID-19 through SARS-CoV-2 spike glycoprotein, Springer, 2020, pp. 1-9.

[29] Q. Zhang, R. Xiang, S. Huo, Y. Zhou, S. Jiang, Q. Wang, F. Yu, Molecular mechanism of interaction between SARS-CoV-2 and host cells and interventional therapy, Signal Transduction and Targeted Therapy 6(1) (2021) 233

[30] P. Zhou, X.-L. Yang, X.-G. Wang, B. Hu, L. Zhang, W. Zhang, H.-R. Si, Y. Zhu, B. Li, C.-L. Huang, A pneumonia outbreak associated with a new coronavirus of probable bat origin, nature 579(7798) (2020) 270-273.

[31] J. Shang, G. Ye, K. Shi, Y. Wan, C. Luo, H. Aihara, Q. Geng, A. Auerbach,
F. Li, Structural basis of receptor recognition by SARS-CoV-2, Nature 581(7807) (2020) 221-224.

[32] G. Lu, Y. Hu, Q. Wang, J. Qi, F. Gao, Y. Li, Y. Zhang, W. Zhang, Y. Yuan, J. Bao, Molecular basis of binding between novel human coronavirus MERS-CoV and its receptor CD26, Nature 500(7461) (2013) 227-231.

[33] V. Chaudhary, A. Royal, M. Chavali, S.K. Yadav, Advancements in research and development to combat COVID-19 using nanotechnology, Nanotechnology for Environmental Engineering 6(1) (2021) 8

[34] Y. Rasmi, K.S. Saloua, M. Nemati, J.R. Choi, Recent Progress in Nanotechnology for COVID-19 Prevention, Diagnostics and Treatment, Nanomaterials 11(7) (2021) 1788

[35] S. Al-Halifa, L. Gauthier, D. Arpin, S. Bourgault, D. Archambault, Nanoparticle-based vaccines against respiratory viruses, Frontiers in immunology 10 (2019) 22.

[36] S. Priyadarsini, S. Mukherjee, M. Mishra, Nanoparticles used in dentistry: A review, Journal of oral biology and craniofacial research 8(1) (2018) 58-67.

[37] F. Vahedifard, K. Chakravarthy, Nanomedicine for COVID-19: The role of nanotechnology in the treatment and diagnosis of COVID-19, Emergent materials (2021) 1-25.

[38] L. Yang, W. Li, M. Kirberger, W. Liao, J. Ren, Design of nanomaterial based systems for novel vaccine development, Biomaterials science 4(5) (2016) 785-802. [39] Y. Katayama, T. Ohgi, Y. Mitoma, E. Hifumi, N.J.A. Egashira, b. chemistry, Detection of influenza virus by a biosensor based on the method combining electrochemiluminescence on binary SAMs modified Au electrode with an immunoliposome encapsulating Ru (II) complex, 408(22) (2016) 5963-5971.

[40] A. Mokhtarzadeh, M.J.I. Bouzari, Detection of the frequency of the novel TT virus by PCR and its role in the induction of hepatic injuries in blood donors in West Azarbaijan, Iran, 5 (2009) 25-31.

[41] A. Mokhtarzadeh, R. Eivazzadeh-Keihan, P. Pashazadeh, M. Hejazi, N. Gharaatifar, M. Hasanzadeh, B. Baradaran, M. de la Guardia, Nanomaterial-based biosensors for detection of pathogenic virus, TrAC Trends in Analytical Chemistry 97 (2017) 445-457.

[42] D.S. Chauhan, R. Prasad, R. Srivastava, M. Jaggi, S.C. Chauhan, M.M. Yallapu, Comprehensive review on current interventions, diagnostics, and nanotechnology perspectives against SARS-CoV-2, Bioconjugate Chemistry 31(9) (2020) 2021-2045.

[43] Y.-F. Tu, C.-S. Chien, A.A. Yarmishyn, Y.-Y. Lin, Y.-H. Luo, Y.-T. Lin, W.-Y. Lai, D.-M. Yang, S.-J. Chou, Y.-P. Yang, A review of SARS-CoV-2 and the ongoing clinical trials, International journal of molecular sciences 21(7) (2020) 2657. [44] T. Arun, S.K. Verma, P.K. Panda, R.J. Joseyphus, E. Jha, A. Akbari-Fakhrabadi, P. Sengupta, D. Ray, V. Benitha, K.J.M.S. Jeyasubramanyan, E. C, Facile synthesized novel hybrid graphene oxide/cobalt ferrite magnetic nanoparticles based surface coating material inhibit bacterial secretion pathway for antibacterial effect, 104 (2019) 109932

[45] S.K. Verma, E. Jha, P.K. Panda, J.K. Das, A. Thirumurugan, M. Suar, S.J.N. Parashar, Molecular aspects of core-shell intrinsic defect induced enhanced antibacterial activity of $\mathrm{ZnO}$ nanocrystals, 13(1) (2018) 43-68.

[46] B.K. Das, S.K. Verma, T. Das, P.K. Panda, K. Parashar, M. Suar, S.J.C.b.i. Parashar, Altered electrical properties with controlled copper doping in $\mathrm{ZnO}$ nanoparticles infers their cytotoxicity in macrophages by ROS induction and apoptosis, 297 (2019) 141-154

[47] P. Kumari, P.K. Panda, E. Jha, N. Pramanik, K. Nisha, K. Kumari, N. Soni, M.A. Mallick, S.K.J.N. Verma, Molecular insight to in vitro biocompatibility of phytofabricated copper oxide nanoparticles with human embryonic kidney cells, 13(19) (2018) 2415-2433.

[48] S.S. Jeremiah, K. Miyakawa, T. Morita, Y. Yamaoka, A.J.B. Ryo, b.r. communications, Potent antiviral effect of silver nanoparticles on SARS-CoV-2, 533(1) (2020) 195-200.

[49] Z. Zhao, H. Cui, W. Song, X. Ru, W. Zhou, X.J.B. Yu, A simple magnetic nanoparticles-based viral RNA extraction method for efficient detection of SARSCoV-2, (2020)

[50] T.T.S. Lew, K.M.M. Aung, S.Y. Ow, S.N. Amrun, L. Sutarlie, L.F. Ng, X.J.A.n. Su, Epitope-Functionalized Gold Nanoparticles for Rapid and Selective Detection of SARS-CoV-2 IgG Antibodies, (2021).

[51] M. Soloviev, G. Siligardi, D. Roccatano, E.J.J.o.C. Ferrari, I. Science, Modelling the adsorption of proteins to nanoparticles at the solid-liquid interface, (2021). [52] F. De Maio, V. Palmieri, G. Babini, A. Augello, I. Palucci, G. Perini, A. Salustri, P. Spilman, M. De Spirito, M.J.I. Sanguinetti, Graphene nanoplatelet and Graphene oxide functionalization of face mask materials inhibits infectivity of trapped SARS-CoV-2, 24(7) (2021) 102788.

[53] F. Zhang, Z. Wang, M.G. Vijver, W.J.J.E. Peijnenburg, e. safety, Probing nano-QSAR to assess the interactions between carbon nanoparticles and a SARS- 
CoV-2 RNA fragment, 219 (2021) 112357.

[54] J.N. Wankar, V.K. Chaturvedi, C. Bohara, M.P. Singh, R.A.J.F.i.N. Bohara, Role of Nanomedicine in Management and Prevention of COVID-19, 2 (2020) 8. [55] M. Khanal, T. Vausselin, A. Barras, O. Bande, K. Turcheniuk, M. Benazza, V. Zaitsev, C.M. Teodorescu, R. Boukherroub, A. Siriwardena, J. Dubuisson, S. Szunerits, Phenylboronic-acid-modified nanoparticles: potential antiviral therapeutics, ACS applied materials \& interfaces 5(23) (2013) 12488-98.

[56] D. Kumar, K. Kumari, A. Jayaraj, V. Kumar, R.V. Kumar, S.K. Dass, R. Chandra, P. Singh, Understanding the binding affinity of noscapines with protease of SARS-CoV-2 for COVID-19 using MD simulations at different temperatures, Journal of Biomolecular Structure and Dynamics 39(7) (2021) 2659-2672.

[57] H. Khalilpour, P. Shafiee, A. Darbandi, M. Yusuf, S. Mahmoudi, Z.M. Goudarzi, S. Mirzamohammadi, Application of Polyoxometalate-based composites for sensor systems: A review, Journal of Composites and Compounds 3(7) (2021) 129-139.

[58] K. O’Dowd, K.M. Nair, P. Forouzandeh, S. Mathew, J. Grant, R. Moran, J. Bartlett, J. Bird, S.C. Pillai, Face masks and respirators in the fight against the COVID-19 pandemic: A review of current materials, advances and future perspectives, Materials 13(15) (2020) 3363.

[59] D. Aydemir, N.N. Ulusu, Correspondence: Angiotensin-converting enzyme 2 coated nanoparticles containing respiratory masks, chewing gums and nasal filters may be used for protection against COVID-19 infection, Travel medicine and infectious disease 37 (2020) 101697.

[60] S.P. Varahachalam, B. Lahooti, M. Chamaneh, S. Bagchi, T. Chhibber, K. Morris, J.F. Bolanos, N.-Y. Kim, A. Kaushik, Nanomedicine for the SARS-CoV-2: state-of-the-art and future prospects, International journal of nanomedicine 16 (2021) 539 .

[61] L.A. Dykman, Gold nanoparticles for preparation of antibodies and vaccines against infectious diseases, Expert Rev Vaccines 19(5) (2020) 465-477.

[62] H.-W. Chen, C.-Y. Huang, S.-Y. Lin, Z.-S. Fang, C.-H. Hsu, J.-C. Lin, Y.-I. Chen, B.-Y. Yao, C.-M.J.J.B. Hu, Synthetic virus-like particles prepared via protein corona formation enable effective vaccination in an avian model of coronavirus infection, 106 (2016) 111-118

[63] H. Sekimukai, N. Iwata-Yoshikawa, S. Fukushi, H. Tani, M. Kataoka, T. Suzuki, H. Hasegawa, K. Niikura, K. Arai, N. Nagata, Gold nanoparticle-adjuvanted $\mathrm{S}$ protein induces a strong antigen-specific IgG response against severe acute respiratory syndrome-related coronavirus infection, but fails to induce protective antibodies and limit eosinophilic infiltration in lungs, Microbiology and immunology 64(1) (2020) 33-51.

[64] N.H. Abd Ellah, S.F. Gad, K. Muhammad, G. E Batiha, H.F.J.N. Hetta, Nanomedicine as a promising approach for diagnosis, treatment and prophylaxis against COVID-19, 15(21) (2020) 2085-2102.

[65] L.M. Marques Neto, A. Kipnis, A.P.J.F.i.i. Junqueira-Kipnis, Role of metallic nanoparticles in vaccinology: implications for infectious disease vaccine development, 8 (2017) 239

[66] Q.-Y. Cai, S.H. Kim, K.S. Choi, S.Y. Kim, S.J. Byun, K.W. Kim, S.H. Park, S.K. Juhng, K.-H.J.I.r. Yoon, Colloidal gold nanoparticles as a blood-pool contrast agent for X-ray computed tomography in mice, 42(12) (2007) 797-806.

[67] A.K. Lytton-Jean, R. Langer, D.G.J.S. Anderson, Five years of siRNA delivery: spotlight on gold nanoparticles, 7(14) (2011) 1932-1937.

[68] X. Huang, M. Li, Y. Xu, J. Zhang, X. Meng, X. An, L. Sun, L. Guo, X. Shan, J.J.A.a.m. Ge, interfaces, Novel gold nanorod-based HR1 peptide inhibitor for Middle East respiratory syndrome coronavirus, 11(22) (2019) 19799-19807.

[69] R. Itani, M. Tobaiqy, A.J.T. Al Faraj, Optimizing use of theranostic nanoparticles as a life-saving strategy for treating COVID-19 patients, 10(13) (2020) 5932. [70] J. Manso, M.L. Mena, P. Yanez-Sedeno, J.M.J.A.b. Pingarrón, Bienzyme amperometric biosensor using gold nanoparticle-modified electrodes for the determination of inulin in foods, 375(2) (2008) 345-353.

[71] R. Cui, H. Huang, Z. Yin, D. Gao, J.-J.J.B. Zhu, Bioelectronics, Horseradish peroxidase-functionalized gold nanoparticle label for amplified immunoanalysis based on gold nanoparticles/carbon nanotubes hybrids modified biosensor, 23(11) (2008) $1666-1673$.

[72] Y. Huang, T. Xu, W. Wang, Y. Wen, K. Li, L. Qian, X. Zhang, G. Liu, Lateral flow biosensors based on the use of micro- and nanomaterials: a review on recent developments, Mikrochimica acta 187(1) (2019) 70 .

[73] J.J. Mock, D.R. Smith, S.J.N.1. Schultz, Local refractive index dependence of plasmon resonance spectra from individual nanoparticles, 3(4) (2003) 485-491. [74] J.C. Huang, Y.-F. Chang, K.-H. Chen, L.-C. Su, C.-W. Lee, C.-C. Chen, Y.M.A. Chen, C. Chou, Detection of severe acute respiratory syndrome (SARS) coronavirus nucleocapsid protein in human serum using a localized surface plasmon coupled fluorescence fiber-optic biosensor, Biosensors and Bioelectronics $25(2)(2009) 320-325$
[75] L.A. Layqah, S. Eissa, An electrochemical immunosensor for the corona virus associated with the Middle East respiratory syndrome using an array of gold nanoparticle-modified carbon electrodes, Microchimica Acta 186(4) (2019) 224.

[76] E.M. Abed, S.M. Hoseini-Alfatemi, H. Sabati, M.A.K. Gaskarei, K. Delpasand, M.J.J.o.C.B.R. Ghasemi, Use of nanotechnology in the diagnosis and treatment of coronavirus, (2021).

[77] Y.V. Liu, M.J. Massare, D.L. Barnard, T. Kort, M. Nathan, L. Wang, G. Smith, Chimeric severe acute respiratory syndrome coronavirus (SARS-CoV) S glycoprotein and influenza matrix 1 efficiently form virus-like particles (VLPs) that protect mice against challenge with SARS-CoV, Vaccine 29(38) (2011) 6606-6613.

[78] C. Poon, A.A.J.N.E. Patel, Organic and inorganic nanoparticle vaccines for prevention of infectious diseases, 1(1) (2020) 012001

[79] B.-K. Jung, Y.K. Lee, J. Hong, H. Ghandehari, C.-O.J.A.n. Yun, Mild hyperthermia induced by gold nanorod-mediated plasmonic photothermal therapy enhances transduction and replication of oncolytic adenoviral gene delivery, 10(11) (2016) 10533-10543.

[80] S. Ghosh, E. Mostafavi, A. Vernet-Crua, T.J.J.N.M.N.D.j. Webster, Nanomaterial Approaches for the Prevention, Diagnosis and Treatment of COVID-19: A Paradigm Shift, 280 (2020) 2

[81] C. Huang, T. Wen, F.-J. Shi, X.-Y. Zeng, Y.-J. Jiao, Rapid Detection of IgM Antibodies against the SARS-CoV-2 Virus via Colloidal Gold Nanoparticle-Based Lateral-Flow Assay, ACS Omega 5(21) (2020) 12550-12556.

[82] S. Kumar, C. Kempinski, X. Zhuang, A. Norris, S. Mafu, J. Zi, S.A. Bell, S.E. Nybo, S.E. Kinison, Z. Jiang, S. Goklany, K.B. Linscott, X. Chen, Q. Jia, S.D. Brown, J.L. Bowman, P.C. Babbitt, R.J. Peters, F. Chen, J. Chappell, Molecular Diversity of Terpene Synthases in the Liverwort Marchantia polymorpha The Plant Cell 28(10) (2016) 2632-2650.

[83] M.C. Sportelli, M. Izzi, E.A. Kukushkina, S.I. Hossain, R.A. Picca, N. Ditaranto, N. Cioffi, Can Nanotechnology and Materials Science Help the Fight against SARS-CoV-2?, 10(4) (2020) 802

[84] C. Balagna, S. Perero, E. Percivalle, E.V. Nepita, M. Ferraris, Virucidal effect against coronavirus SARS-CoV-2 of a silver nanocluster/silica composite sputtered coating, Open Ceramics 1 (2020) 100006.

[85] J. Daraei, Production and characterization of PCL (Polycaprolactone) coated TCP/nanoBG composite scaffolds by sponge foam method for orthopedic applications, Journal of Composites and Compounds 2(2) (2020) 44-49.

[86] E.V.R. Campos, A.E.S. Pereira, J.L. de Oliveira, L.B. Carvalho, M. Guilger-Casagrande, R. de Lima, L.F. Fraceto, How can nanotechnology help to combat COVID-19? Opportunities and urgent need, Journal of Nanobiotechnology 18(1) (2020) 125.

[87] S. Bhattacharjee, R. Joshi, A.A. Chughtai, C.R. Macintyre, Graphene Modified Multifunctional Personal Protective Clothing, 6(21) (2019) 1900622.

[88] K. Shirvanimoghaddam, M.K. Akbari, R. Yadav, A.K. Al-Tamimi, M. Naebe, Fight against COVID-19: The case of antiviral surfaces, APL Materials 9(3) (2021) 031112 .

[89] S. Basak, G.J.N.-S. Packirisamy, Nano-Objects, Nano-based antiviral coatings to combat viral infections, 24 (2020) 100620.

[90] M. Rai, S. Bonde, A. Yadav, A. Bhowmik, S. Rathod, P. Ingle, A. Gade, Nanotechnology as a Shield against COVID-19: Current Advancement and Limitations, 13(7) (2021) 1224

[91] M. Maywald, I. Wessels, L.J.I.j.o.m.s. Rink, Zinc signals and immunity, 18(10) (2017) 2222.

[92] D. Beyersmann, H.J.B. Haase, Functions of zinc in signaling, proliferation and differentiation of mammalian cells, 14(3) (2001) 331-341.

[93] F. Niazvand, A. Cheshmi, M. Zand, R. NasrAzadani, B. Kumari, A. Raza, S. Nasibi, An overview of the development of composites containing $\mathrm{Mg}$ and $\mathrm{Zn}$ for drug delivery, Journal of Composites and Compounds 2(5) (2020) 193-204

[94] A. Pormohammad, N.K. Monych, R.J. Turner, Zinc and SARS-CoV-2: A molecular modeling study of $\mathrm{Zn}$ interactions with RNA-dependent RNA-polymerase and 3C-like proteinase enzymes, Int J Mol Med 47(1) (2021) 326-334

[95] S.A. Read, S. Obeid, C. Ahlenstiel, G.J.A.i.n. Ahlenstiel, The role of zinc in antiviral immunity, 10(4) (2019) 696-710

[96] A.J. Te Velthuis, S.H. van den Worm, A.C. Sims, R.S. Baric, E.J. Snijder, M.J.J.P.p. van Hemert, $\mathrm{Zn} 2+$ inhibits coronavirus and arterivirus RNA polymerase activity in vitro and zinc ionophores block the replication of these viruses in cell culture, 6(11) (2010) e1001176.

[97] C.-C. Lee, C.-J. Kuo, M.-F. Hsu, P.-H. Liang, J.-M. Fang, J.-J. Shie, A.H.J.J.F.1. Wang, Structural basis of mercury-and zinc-conjugated complexes as SARS-CoV 3C-like protease inhibitors, 581(28) (2007) 5454-5458.

[98] A. Pormohammad, N.K. Monych, R.J. Turner, Zinc and SARS-CoV-2: A molecular modeling study of Zn interactions with RNA-dependent RNA-polymerase and $3 \mathrm{C}$-like proteinase enzymes, International journal of molecular medicine $47(1)$ 
(2021) 326-334

[99] P. Bonaventura, G. Benedetti, F. Albarède, P.J.A.r. Miossec, Zinc and its role in immunity and inflammation, 14(4) (2015) 277-285.

[100] H.H. Sandstead, A.S.J.A.j.o.p.h. Prasad, Zinc intake and resistance to H1N1 influenza, 100(6) (2010) 970-971.

[101] K. Wu, R. Saha, D. Su, V.D. Krishna, J. Liu, M.C.-J. Cheeran, J.-P.J.A.A.N.M. Wang, Magnetic-nanosensor-based virus and pathogen detection strategies before and during covid-19, 3(10) (2020) 9560-9580.

[102] M.-H. Lin, D.C. Moses, C.-H. Hsieh, S.-C. Cheng, Y.-H. Chen, C.-Y. Sun, C.-Y.J.A.r. Chou, Disulfiram can inhibit MERS and SARS coronavirus papain-like proteases via different modes, 150 (2018) 155-163.

[103] H. Zhang, J.M. Penninger, Y. Li, N. Zhong, A.S.J.I.c.m. Slutsky, Angiotensin-converting enzyme 2 (ACE2) as a SARS-CoV-2 receptor: molecular mechanisms and potential therapeutic target, 46(4) (2020) 586-590.

[104] Y. Yan, H. Tao, J. He, S.-Y. Huang, The HDOCK server for integrated protein-protein docking, Nature protocols 15(5) (2020) 1829-1852.

[105] D. Wrapp, N. Wang, K.S. Corbett, J.A. Goldsmith, C.-L. Hsieh, O. Abiona, B.S. Graham, J.S. McLellan, Cryo-EM structure of the 2019-nCoV spike in the prefusion conformation, Science 367(6483) (2020) 1260-1263.

[106] R. Speth, E. Carrera, M. Jean-Baptiste, A. Joachim, A.J.T.F.j. Linares, Concentration-dependent effects of zinc on angiotensin-converting enzyme-2 activity (1067.4), 28 (2014) 1067.4.

[107] A.V. Skalny, L. Rink, O.P. Ajsuvakova, M. Aschner, V.A. Gritsenko, S.I. Alekseenko, A.A. Svistunov, D. Petrakis, D.A. Spandidos, J.J.I.j.o.m.m. Aaseth, Zinc and respiratory tract infections: Perspectives for COVID-19, 46(1) (2020) $17-26$.

[108] E. Laurini, D. Marson, S. Aulic, A. Fermeglia, S. Pricl, Computational Mutagenesis at the SARS-CoV-2 Spike Protein/Angiotensin-Converting Enzyme 2 Binding Interface: Comparison with Experimental Evidence, ACS nano 15(4) (2021) 6929-6948

[109] L.A. Pittet, L. Hall-Stoodley, M.R. Rutkowski, A.G.J.A.j.o.r.c. Harmsen, $\mathrm{m}$. biology, Influenza virus infection decreases tracheal mucociliary velocity and clearance of Streptococcus pneumoniae, 42(4) (2010) 450-460.

[110] A. Darma, I.G.M.R.G. Ranuh, W. Merbawani, R.A. Setyoningrum, B. Hidajat, S.N. Hidayati, A. Endaryanto, S.M.J.T.I.B.J. Sudarmo, Zinc supplementation effect on the bronchial cilia length, the number of cilia, and the number of intact bronchial cell in zinc deficiency rats, 12(1) (2020) 78-84.

[111] K. Berg, G. Bolt, H. Andersen, T.C.J.J.o.I. Owen, C. Research, Zinc potentiates the antiviral action of human IFN- $\alpha$ tenfold, 21(7) (2001) 471-474.

[112] D. Khera, S. Singh, P. Purohit, P. Sharma, K.J.T.T.J. Singh, Prevalence of Zinc Deficiency and the Effect of Zinc Supplementation on the Prevention of Acute Respiratory Infections, 21(6) (2020) 371.

[113] I. Wessels, H. Haase, G. Engelhardt, L. Rink, P.J.T.J.o.n.b. Uciechowski, Zinc deficiency induces production of the proinflammatory cytokines IL-1 $\beta$ and $\mathrm{TNF} \alpha$ in promyeloid cells via epigenetic and redox-dependent mechanisms, 24(1) (2013) 289-297.

[114] E. Rosenkranz, C.H. Metz, M. Maywald, R.D. Hilgers, I. Weßels, T. Senff, H. Haase, M. Jäger, M. Ott, R.J.M.n. Aspinall, f. research, Zinc supplementation induces regulatory $\mathrm{T}$ cells by inhibition of Sirt-1 deacetylase in mixed lymphocyte cultures, 60(3) (2016) 661-671.

[115] C. Wu, X. Chen, Y. Cai, X. Zhou, S. Xu, H. Huang, L. Zhang, X. Zhou, C. Du, Y.J.J.i.m. Zhang, Risk factors associated with acute respiratory distress syndrome and death in patients with coronavirus disease 2019 pneumonia in Wuhan, China, 180(7) (2020) 934-943.

[116] A. Tsatsakis, N.V. Tyshko, A.O. Docea, S.I. Shestakova, Y.S. Sidorova, N.A. Petrov, O. Zlatian, M. Mach, T. Hartung, V.A.J.T.1. Tutelyan, The effect of chronic vitamin deficiency and long term very low dose exposure to 6 pesticides mixture on neurological outcomes-a real-life risk simulation approach, 315 (2019) 96-106. [117] M.G. Skalnaya, A.V.J.T.P.H.o.T.S.U. Skalny, Essential trace elements in human health: a physician's view, (2018) 224.

[118] M.S.J.C. Razzaque, s.b. journal, COVID-19 pandemic: Can zinc supplementation provide an additional shield against the infection, (2021).

[119] R.O. Suara, J.E.J.A.a. Crowe Jr, chemotherapy, Effect of zinc salts on respiratory syncytial virus replication, 48(3) (2004) 783-790.

[120] J. Shang, Y. Wan, C. Luo, G. Ye, Q. Geng, A. Auerbach, F.J.P.o.t.N.A.o.S. Li, Cell entry mechanisms of SARS-CoV-2, 117(21) (2020) 11727-11734.

[121] V.B. Patel, J.-C. Zhong, M.B. Grant, G.Y.J.C.r. Oudit, Role of the ACE2/angiotensin 1-7 axis of the renin-angiotensin system in heart failure, 118(8) (2016) 1313-1326.

[122] M.C. Lee, Y.-K. Chen, Y.-J. Hsu, B.-R.J.b. Lin, Zinc supplement augments the suppressive effects of repurposed drugs of NF-kappa B inhibitor on ACE2 expression in human lung cell lines in vitro, (2021).
[123] P. Carlucci, T. Ahuja, C.M. Petrilli, H. Rajagopalan, S. Jones, J.J.M. Rahimian, Hydroxychloroquine and azithromycin plus zinc vs hydroxychloroquine and azithromycin alone: outcomes in hospitalized COVID-19 patients, (2020).

[124] Y.-K. Chen, T.-T. Huang, C.-W. Chang, M.-C. Lee, B.-R. Lin, Y.-P. Lu, Y.-J. Hsu, C.-Y.J.b. Chuang, Azithromycin Plus Zinc Sulfate Rapidly and Synergistically Suppresses IkB $\alpha$-Mediated In Vitro Human Airway Cell ACE2 Expression for SARS-CoV-2 Entry, (2021).

[125] M. Rezaei, S.M. Mirkazemi, S.J.J.o.S. Alamolhoda, N. Magnetism, The Role of PVA Surfactant on Magnetic Properties of $\mathrm{MnFe}_{2} \mathrm{O}_{4}$ Nanoparticles Synthesized by Sol-Gel Hydrothermal Method, (2021) 1-12.

[126] H. Rashidzadeh, H. Danafar, H. Rahimi, F. Mozafari, M. Salehiabar, M.A. Rahmati, S. Rahamooz-Haghighi, N. Mousazadeh, A. Mohammadi, Y.N.J.N. Ertas, Nanotechnology against the novel coronavirus (severe acute respiratory syndrome coronavirus 2): diagnosis, treatment, therapy and future perspectives, 16(6) (2021) 497-516.

[127] F. Sharifianjazi, M. Irani, A. Esmaeilkhanian, L. Bazli, M.S. Asl, H.W. Jang, S.Y. Kim, S. Ramakrishna, M. Shokouhimehr, R.S. Varma, Polymer incorporated magnetic nanoparticles: Applications for magnetoresponsive targeted drug delivery, Materials Science and Engineering: B 272 (2021) 115358.

[128] S. Jindal, P. Gopinath, Nanotechnology based approaches for combatting COVID-19 viral infection, Nano Express 1(2) (2020) 022003.

[129] H.-W. Chen, Z.-S. Fang, Y.-T. Chen, Y.-I. Chen, B.-Y. Yao, J.-Y. Cheng, C.Y. Chien, Y.-C. Chang, C.-M.J. Hu, Targeting and Enrichment of Viral Pathogen by Cell Membrane Cloaked Magnetic Nanoparticles for Enhanced Detection, ACS applied materials \& interfaces 9(46) (2017) 39953-39961.

[130] J. Yang, Inhibition of SARS-CoV-2 Replication by Acidizing and RNA Lyase-Modified Carbon Nanotubes Combined with Photodynamic Thermal Effect, J Explor Res Pharmacol 5(2) (2020) 18-23.

[131] F. Niazvand, P.R. Wagh, E. Khazraei, M. Borzouyan Dastjerdi, C. Patil, I.A. Najar, Application of carbon allotropes composites for targeted cancer therapy drugs: A review, Journal of Composites and Compounds 3(7) (2021) 140-151.

[132] Y.-T. Yeh, Y. Tang, A. Sebastian, A. Dasgupta, N. Perea-Lopez, I. Albert, H. Lu, M. Terrones, S.-Y. Zheng, Tunable and label-free virus enrichment for ultrasensitive virus detection using carbon nanotube arrays, 2(10) (2016) J. Science Advances.

[133] I. Tajzad, E. Ghasali, Production methods of CNT-reinforced Al matrix composites: a review, Journal of Composites and Compounds 2(2) (2020) 1-9.

[134] R.L. Pinals, F. Ledesma, D. Yang, N. Navarro, S. Jeong, J.E. Pak, L. Kuo, Y.-C. Chuang, Y.-W. Cheng, H.-Y. Sun, M.P. Landry, Rapid SARS-CoV-2 Spike Protein Detection by Carbon Nanotube-Based Near-Infrared Nanosensors, Nano Letters 21(5) (2021) 2272-2280.

[135] S. Mohammadi, M. Heidarizadeh, M. Entesari, A. Esmailpour, M. Esmailpour, R. Moradi, N. Sakhaee, E. Doustkhah, In silico investigation on the inhibiting role of nicotine/caffeine by blocking the S protein of SARS-CoV-2 versus ACE2 receptor, Microorganisms 8(10) (2020) 1600.

[136] M. Hussain, N. Jabeen, F. Raza, S. Shabbir, A.A. Baig, A. Amanullah, B. Aziz, Structural variations in human ACE2 may influence its binding with SARSCoV-2 spike protein, Journal of medical virology 92(9) (2020) 1580-1586.

[137] M.A. Alam, M.H. Asoushe, P. Pourhakkak, L. Gritsch, A. Alipour, S. Mohammadi, Preparation of bioactive polymer-based composite by different techniques and application in tissue engineering: A review, Journal of Composites and Compounds 3(8) (2021) 194-205.

[138] B.S. Miller, L. Bezinge, H.D. Gliddon, D. Huang, G. Dold, E.R. Gray, J. Heaney, P.J. Dobson, E. Nastouli, J.J.L. Morton, R.A. McKendry, Spin-enhanced nanodiamond biosensing for ultrasensitive diagnostics, Nature 587(7835) (2020) 588-593.

[139] M. Nasrollahzadeh, M. Sajjadi, G.J. Soufi, S. Iravani, R.S. Varma, Nanomaterials and Nanotechnology-Associated Innovations against Viral Infections with a Focus on Coronaviruses, 10(6) (2020) 1072.

[140] A. Stein, Z. Wang, M.A. Fierke, Functionalization of Porous Carbon Materials with Designed Pore Architecture, 21(3) (2009) 265-293.

[141] T. Matsushita, H. Suzuki, N. Shirasaki, Y. Matsui, K. Ohno, Adsorptive virus removal with super-powdered activated carbon, Separation and Purification Technology 107 (2013) 79-84.

[142] Y. Rasmi, K.S. Saloua, M. Nemati, J.R. Choi, Recent Progress in Nanotechnology for COVID-19 Prevention, Diagnostics and Treatment, 11(7) (2021) 1788. [143] Y. Zamani, A. Zareein, L. Bazli, R. NasrAzadani, B. Pasha Mahammod, S. Nasibi, A. Modarresi Chahardehi, Nanodiamond-containing composites for tissue sca?olds and surgical implants: A review, Journal of Composites and Compounds 2(5) (2020) 215-227.

[144] M.A. Hasan, A. Carmel Mary Esther, A. Dey, A.K. Mukhopadhyay, A review on coronavirus survivability on material's surfaces: present research scenarios, 
technologies and future directions, Surface Engineering 36(12) (2020) 1226-1239. [145] V. Vamvakaki, N.A. Chaniotakis, Carbon nanostructures as transducers in biosensors, Sensors and Actuators B: Chemical 126(1) (2007) 193-197.

[146] F. Valentini, M. Carbone, G. Palleschi, Carbon nanostructured materials for applications in nano-medicine, cultural heritage, and electrochemical biosensors, Analytical and Bioanalytical Chemistry 405(2) (2013) 451-465.

[147] Z.J.N.-m.1. Zhu, An overview of carbon nanotubes and graphene for biosensing applications, 9(3) (2017) 1-24.

[148] K.R. Ratinac, W. Yang, J.J. Gooding, P. Thordarson, F.J.E. Braet, Graphene and related materials in electrochemical sensing, 23(4) (2011) 803-826.

[149] H. Ma, D. Wu, Z. Cui, Y. Li, Y. Zhang, B. Du, Q.J.A.L. Wei, Graphene-based optical and electrochemical biosensors: a review, 46(1) (2013) 1-17.

[150] E. Asadi, A. Fassadi Chimeh, S. Hosseini, S. Rahimi, B. Sarkhosh, L. Bazli, R. Bashiri, A.H. Vakili Tahmorsati, A review of clinical applications of graphene quantum dot-based composites, Journal of Composites and Compounds 1(1) (2019) 31-40.

[151] G. Wu, M. Meyyappan, K.W.C.J.S. Lai, Simulation of graphene field-effect transistor biosensors for bacterial detection, 18(6) (2018) 1715.

[152] R. Abedini-Nassab, N. Mahdaviyan, Recent Patents and Advances on Nanotechnologies against Coronavirus, Recent Patents on Nanotechnology, 15(4) (2021) 322-330

[153] R. Antiochia, Nanobiosensors as new diagnostic tools for SARS, MERS and COVID-19: from past to perspectives, Microchimica Acta 187(12) (2020) 1-13. [154] J.E. Contreras-Naranjo, O.J.B. Aguilar, Suppressing non-specific binding of proteins onto electrode surfaces in the development of electrochemical immunosensors, 9(1) (2019) 15 .

[155] V.J.N. Uskoković, Why have nanotechnologies been underutilized in the global uprising against the coronavirus pandemic?, 15(17) (2020) 1719-1734

[156] A. Kazemzadeh, M.A. Meshkat, H. Kazemzadeh, M. Moradi, R. Bahrami, R. Pouriamanesh, Preparation of graphene nanolayers through surfactant-assisted pure shear milling method, Journal of Composites and Compounds 1(1) (2019) 22-26.

[157] R. Gupta, P. Sagar, N. Priyadarshi, S. Kaul, R. Sandhir, V. Rishi, N.K.J.F.i.N. Singhal, Nanotechnology-based approaches for the detection of SARS-CoV-2, 2 (2020) 6.

[158] X. Du, R. Xiao, H. Fu, Z. Yuan, W. Zhang, L. Yin, C. He, C. Li, J. Zhou, G.J.M.S. Liu, E. C, Hypericin-loaded graphene oxide protects ducks against a novel duck reovirus, 105 (2019) 110052.

[159] O. Akhavan, M. Choobtashani, E.J.T.J.o.P.C.C. Ghaderi, Protein degradation and RNA efflux of viruses photocatalyzed by graphene-tungsten oxide composite under visible light irradiation, 116(17) (2012) 9653-9659.

[160] S. Ye, K. Shao, Z. Li, N. Guo, Y. Zuo, Q. Li, Z. Lu, L. Chen, Q. He, H.J.A.a.m. Han, interfaces, Antiviral activity of graphene oxide: how sharp edged structure and charge matter, 7(38) (2015) 21571-21579.

[161] Z. Song, X. Wang, G. Zhu, Q. Nian, H. Zhou, D. Yang, C. Qin, R.J.S. Tang, Virus capture and destruction by label-free graphene oxide for detection and disinfection applications, 11(9-10) (2015) 1171-1176.

[162] G. Seo, G. Lee, M.J. Kim, S.-H. Baek, M. Choi, K.B. Ku, C.-S. Lee, S. Jun, D. Park, H.G.J.A.n. Kim, Rapid detection of COVID-19 causative virus (SARS-CoV-2) in human nasopharyngeal swab specimens using field-effect transistor-based biosensor, 14(4) (2020) 5135-5142.

[163] D. Peer, J.M. Karp, S. Hong, O.C. Farokhzad, R. Margalit, R.J.N.n. Langer, Nanocarriers as an emerging platform for cancer therapy, 2(12) (2007) 751-760.

[164] S. Manivannan, K.J.A.o.c. Ponnuchamy, Quantum dots as a promising agent to combat COVID-19, 34(10) (2020) e5887.

[165] S. Nikazar, V.S. Sivasankarapillai, A. Rahdar, S. Gasmi, P. Anumol, M.S.J.B.r. Shanavas, Revisiting the cytotoxicity of quantum dots: An in-depth overview, 12(3) (2020) 703-718.

[166] H. Ashiba, Y. Sugiyama, X. Wang, H. Shirato, K. Higo-Moriguchi, K. Taniguchi, Y. Ohki, M.J.B. Fujimaki, Bioelectronics, Detection of norovirus virus-like particles using a surface plasmon resonance-assisted fluoroimmunosensor optimized for quantum dot fluorescent labels, 93 (2017) 260-266.

[167] C. Roh, S.K.J.J.o.C.T. Jo, Biotechnology, Quantitative and sensitive detection of SARS coronavirus nucleocapsid protein using quantum dots-conjugated RNA aptamer on chip, 86(12) (2011) 1475-1479.

[168] S.-L. Liu, Z.-G. Wang, H.-Y. Xie, A.-A. Liu, D.C. Lamb, D.-W.J.C.r. Pang, Single-virus tracking: from imaging methodologies to virological applications, 120(3) (2020) 1936-1979

[169] Á. Serrano-Aroca, K. Takayama, A. Tuñón-Molina, M. Seyran, S.S. Hassan, P. Pal Choudhury, V.N. Uversky, K. Lundstrom, P. Adadi, G.J.A.n. Palù, Carbon-based nanomaterials: promising antiviral agents to combat COVID-19 in the microbial-resistant era, (2021)
[170] A. Łoczechin, K. Séron, A. Barras, E. Giovanelli, S. Belouzard, Y.-T. Chen, N. Metzler-Nolte, R. Boukherroub, J. Dubuisson, S.J.A.a.m. Szunerits, interfaces, Functional carbon quantum dots as medical countermeasures to human coronavirus, 11(46) (2019) 42964-42974

[171] S.R. Ahmed, S.W. Kang, S. Oh, J. Lee, S.J.H. Neethirajan, Chiral zirconium quantum dots: a new class of nanocrystals for optical detection of coronavirus, 4(8) (2018) e00766.

[172] S.R. Ahmed, É. Nagy, S.J.R.a. Neethirajan, Self-assembled star-shaped chiroplasmonic gold nanoparticles for an ultrasensitive chiro-immunosensor for viruses, 7(65) (2017) 40849-40857.

[173] T. Du, J. Liang, N. Dong, J. Lu, Y. Fu, L. Fang, S. Xiao, H.J.A.a.m. Han, interfaces, Glutathione-capped $\mathrm{Ag}_{2} \mathrm{~S}$ nanoclusters inhibit coronavirus proliferation through blockage of viral RNA synthesis and budding, 10(5) (2018) 4369-4378. [174] I.A. Khalil, M.A. Younis, S. Kimura, H.J.B. Harashima, P. Bulletin, Lipid nanoparticles for cell-specific in vivo targeted delivery of nucleic acids, 43(4) (2020) 584-595

[175] A. Walls, Y.J.S. Park, function,, a.o.t.S.C.s.g. Cell, J, Tortorici MA, Wall A, McGuire AT, Veesler D, 181(2) (2020) 281-292.

[176] J. Qi, J. Zhuang, Y. Lu, X. Dong, W. Zhao, W.J.D.d.t. Wu, In vivo fate of lipid-based nanoparticles, 22(1) (2017) 166-172.

[177] I.Z. Sadiq, F.S. Abubakar, B.I.J.J.o.T.U.f.S. Dan-Iya, Role of nanoparticles in tackling COVID-19 pandemic: a bio-nanomedical approach, 15(1) (2021) 198207

[178] C.Y. Yong, H.K. Ong, S.K. Yeap, K.L. Ho, W.S.J.F.i.m. Tan, Recent advances in the vaccine development against Middle East respiratory syndrome-coronavirus, 10 (2019) 1781

[179] S. Talaei, H. Mellatyar, S. Mohammadi, Y. Panahi, P. Kianpour, A. Akbarzadeh, N.J.E.J.O.H. Zarghami, Nanotechnology and COVID-19: Potential Application for Treatment, 1.

[180] M. Alavi, K. Asare-Addo, A.J.B. Nokhodchi, Lectin Protein as a Promising Component to Functionalize Micelles, Liposomes and Lipid NPs against Coronavirus, 8(12) (2020) 580 .

[181] T.T. Tai, T.J. Wu, H.D. Wu, Y.C. Tsai, H.T. Wang, A.M. Wang, S.F. Shih, Y.C.J.C. Chen, T. Science, A Strategy to Treat COVID-19 Disease With Targeted Delivery of Inhalable Liposomal Hydroxychloroquine: A Preclinical Pharmacokinetic Study, 14(1) (2021) 132-136.

[182] I. Feliciello, A.J.H.v. Procino, immunotherapeutics, The pulmonary-proteoliposome as a new therapeutic approach for Coronaviruses, 16(10) (2020) 2373 2373.

[183] G. Li, R. Hu, X.J.H.R. Zhang, Antihypertensive treatment with ACEI/ARB of patients with COVID-19 complicated by hypertension, 43(6) (2020) 588-590.

[184] Z. Abpeikar, R. Mohseni, M.J.T. Safaei, E. Chemistry, The multifunctional nano-immunoliposome design: hypothesis on a therapeutic approach for COVID-19, 103(1) (2021) 118-125.

[185] A.A. Khan, K.S. Allemailem, S.A. Almatroodi, A. Almatroudi, A.H.J.B. Rahmani, Recent strategies towards the surface modification of liposomes: an innovative approach for different clinical applications, 10(4) (2020) 1-15.

[186] R. Jinyu, C. Yi, W. Bin, C. Hong, Z. Ying, S.J.C.J.o.I.T. Zhong, W.M.o.L. Diseases, Study of the Targeting Therapy on Virus Hepatitis: Preparation and Clinical Observation of the Liposomal Drugs for Anti-HBV [J], 1 (1997).

[187] V. Alimardani, S.S. Abolmaali, A.M.J.J.o.N. Tamaddon, Recent advances on nanotechnology-based strategies for prevention, diagnosis, and treatment of coronavirus infections, 2021 (2021).

[188] Q.S. Sun, J.L. Zhang, D.Q. Han, Y.B. Yang, L. Zhu, L. Yu, Characterization and immunological evaluation of chitosan nanoparticles as adjuvants for bovine coronavirus N protein, Applied Mechanics and Materials, Trans Tech Publ, 2012, pp. 113-120.

[189] T. Nochi, Y. Yuki, H. Takahashi, S.-i. Sawada, M. Mejima, T. Kohda, N. Harada, I.G. Kong, A. Sato, N.J.N.m. Kataoka, Nanogel antigenic protein-delivery system for adjuvant-free intranasal vaccines, 9(7) (2010) 572-578.

[190] C. Lee, A. Hwang, L. Jose, J.H. Park, S. Jang, J.K. Song, Y. Kim, Y. Cho, H.B. Jeon, J.-O.J.J.o.I. Jin, E. Chemistry, RAFT/PISA based Ni-NTA polymeric particles for virus-mimetic influenza vaccines, 86 (2020) 35-38.

[191] C.P. Haycook, J.A. Balsamo, E.B. Glass, C.H. Williams, C.C. Hong, A.S Major, T.D.J.I.j.o.n. Giorgio, PEGylated PLGA nanoparticle delivery of eggmanone for T cell modulation: applications in rheumatic autoimmunity, 15 (2020) 1215 .

[192] S.A. Cohen, P.S. Kingma, J. Whitsett, R. Goldbart, T. Traitel, J.J.I.J.o.P. Kost, SP-D loaded PLGA nanoparticles as drug delivery system for prevention and treatment of premature infant's lung diseases, 585 (2020) 119387

[193] S. Amjadi, H. Hamishehkar, M.J.M.S. Ghorbani, E. C, A novel smart PEGylated gelatin nanoparticle for co-delivery of doxorubicin and betanin: A strategy 
for enhancing the therapeutic efficacy of chemotherapy, 97 (2019) 833-841.

[194] N. Sankarakumar, Y.W.J.J.o.M.C.B. Tong, Preventing viral infections with polymeric virus catchers: a novel nanotechnological approach to anti-viral therapy, 1(15) (2013) 2031-2037.

[195] L.C.W. Lin, C.Y. Huang, B.Y. Yao, J.C. Lin, A. Agrawal, A. Algaissi, B.H Peng, Y.H. Liu, P.H. Huang, R.H.J.A.f.m. Juang, Viromimetic STING agonistloaded hollow polymeric nanoparticles for safe and effective vaccination against Middle East respiratory syndrome coronavirus, 29(28) (2019) 1807616.

[196] J.L. McGill, S.M. Kelly, P. Kumar, S. Speckhart, S.L. Haughney, J. Henningson, B. Narasimhan, R.E.J.S.r. Sacco, Efficacy of mucosal polyanhydride nanovaccine against respiratory syncytial virus infection in the neonatal calf, $8(1)$ (2018) 1-15.

[197] J.R. Francica, G.M. Lynn, R. Laga, M.G. Joyce, T.J. Ruckwardt, K.M. Morabito, M. Chen, R. Chaudhuri, B. Zhang, M.J.B.c. Sastry, Thermoresponsive polymer nanoparticles co-deliver RSV F trimers with a TLR-7/8 adjuvant, 27(10) (2016) 2372-2385

[198] G.M. Lynn, R. Laga, P.A. Darrah, A.S. Ishizuka, A.J. Balaci, A.E. Dulcey, M. Pechar, R. Pola, M.Y. Gerner, A.J.N.b. Yamamoto, In vivo characterization of the physicochemical properties of polymer-linked TLR agonists that enhance vaccine immunogenicity, 33(11) (2015) 1201-1210.

[199] M. Dabaghian, A.M. Latifi, M. Tebianian, H. NajmiNejad, S.M.J.V. Ebrahimi, Nasal vaccination with r4M2e. HSP70c antigen encapsulated into N-trimeth- yl chitosan (TMC) nanoparticulate systems: Preparation and immunogenicity in a mouse model, 36(20) (2018) 2886-2895.

[200] S. Dhakal, S. Renu, S. Ghimire, Y. Shaan Lakshmanappa, B.T. Hogshead, N. Feliciano-Ruiz, F. Lu, H. HogenEsch, S. Krakowka, C.W.J.F.i.i. Lee, Mucosal immunity and protective efficacy of intranasal inactivated influenza vaccine is improved by chitosan nanoparticle delivery in pigs, 9 (2018) 934.

[201] C. Sawaengsak, Y. Mori, K. Yamanishi, A. Mitrevej, N.J.A.P. Sinchaipanid, Chitosan nanoparticle encapsulated hemagglutinin-split influenza virus mucosal vaccine, 15(2) (2014) 317-325.

[202] Q. Liu, X. Zheng, C. Zhang, X. Shao, X. Zhang, Q. Zhang, X.J.J.o.m.v. Jiang, Conjugating influenza a (H1N1) antigen to n-trimethylaminoethylmethacrylate chitosan nanoparticles improves the immunogenicity of the antigen after nasal administration, 87(11) (2015) 1807-1815.

[203] S. Okamoto, M. Matsuura, T. Akagi, M. Akashi, T. Tanimoto, T. Ishikawa, M. Takahashi, K. Yamanishi, Y.J.V. Mori, Poly ( $\gamma$-glutamic acid) nano-particles combined with mucosal influenza virus hemagglutinin vaccine protects against influenza virus infection in mice, 27(42) (2009) 5896-5905.

[204] S. Dhakal, J. Hiremath, K. Bondra, Y.S. Lakshmanappa, D.-L. Shyu, K. Ouyang, K.-i. Kang, B. Binjawadagi, J. Goodman, K.J.J.o.C.R. Tabynov, Biodegradable nanoparticle delivery of inactivated swine influenza virus vaccine provides heterologous cell-mediated immune response in pigs, 247 (2017) 194-205. 